\title{
Traumatic brain injury alters dendritic cell differentiation and distribution in lymphoid and non-lymphoid organs
}

\section{Orest Tsymbalyuk ${ }^{1}$, Volodymyr Gerzanich ${ }^{1}$, J Marc Simard ${ }^{1,2,3,4} \&$ Chozha Vendan}

Rathinam $^{5,6}$

${ }^{1}$ Department of Neurosurgery, University of Maryland School of Medicine,

Baltimore, MD, USA

${ }^{2}$ Research Service, Veterans Affairs Maryland Health Care System,

Baltimore, MD, USA

${ }^{3}$ Department of Pathology, University of Maryland School of Medicine,

Baltimore, MD, USA

${ }^{4}$ Department of Physiology, University of Maryland School of Medicine,

Baltimore, MD, USA

${ }^{5}$ Institute of Human Virology, University of Maryland School of Medicine,

17 Baltimore, MD, USA

$18{ }^{6}$ Center for Stem Cell \& Regenerative Medicine, University of Maryland School of Medicine,

Baltimore, MD 21201

\section{Correspondence:}

Chozha V. Rathinam

Associate Professor,

University of Maryland School of Medicine

725 West Lombard Street,

Baltimore, MD 21201

Phone: 410-706-6158

Email: crathinam@ihv.umaryland.edu 


\section{Abstract}

Pathophysiological consequences of traumatic brain injury (TBI) mediated secondary injury remain incompletely understood. In particular, the impact of TBI on the differentiation and maintenance of dendritic cells (DCs), remains completely unknown. Here, we report that DCdifferentiation, maintenance and functions are altered at both early and late phases of TBI. Our studies identify that; 1 . frequencies and absolute numbers of DCs in the spleen and BM are altered at both acute and late phases of TBI; 2. surface expression of key molecules involved in antigen presentation of DCs were affected both at early and late phases of TBI; 3. distribution and functions of tissue-specific DC subsets of both circulatory and lymphatic systems were imbalanced following TBI; 4. early differentiation program of DCs, especially the commitment of hematopoietic stem cells to common DC progenitors, were deregulated after TBI; and 5. intracellular ROS levels were reduced in DC progenitors and differentiated DCs at both early and late phases of TBI. Our data demonstrate, for the first time, that TBI affects the distribution pattern of DCs and induces an imbalance among DC subsets in both lymphoid and nonlymphoid organs. In addition, the current study demonstrates that TBI results in reduced levels of ROS in DCs at both early and late phases of TBI, which may explain altered DC differentiation paradigm following TBI. A deeper understanding on the molecular mechanisms that contribute to DC defects following TBI would be essential and beneficial in treating infections in patients with acute central nervous system (CNS) injuries.

Key Words: Traumatic Brain Injury, Dendritic Cells, Immune system, Dendritic cell progenitors, Reactive Oxygen Species. 


\section{Background}

Traumatic brain injury (TBI)-mediated disabilities and/or deaths pose major threats to global health $[1,2]$. TBI affects $\sim 1.7$ million people each year and contributes to a third of all injury related deaths within the United States [1,3-6]. Even though cellular and molecular mediators that cause severe trauma within the central nervous system (CNS) following TBI have been widely recognized in the recent years, the systemic impact of TBI remains incompletely understood. In particular, knowledge on the cascade of cellular and molecular events leading to TBI-induced "secondary injuries" [7] and its pathophysiological consequences remain elusive.

Dendritic cells (DCs) are the most potent antigen presenting cells and function as the sentinels of the immune system. DCs initiate and shape both innate and adaptive immune responses $[8,9]$. In particular, DCs are essential for the initiation of protective T- and B-cell responses and, thus constitute a frontline defense against invading pathogens[10-12]. Indeed, impaired DC differentiation and functions ultimately results in severe autoimmune deficiencies and enhanced susceptibility to viral, bacterial and fungal infections in mice and humans[1315]. DCs are present in most tissues of the body and can be broadly divided into 3 major groups; 1. conventional or classical DCs (cDCs), which are further subdivided into $\mathrm{cDC} 1$ and $\mathrm{cDC} 2$ subsets, 2. plasmacytoid DCs (pDCs) and 3. monocyte-derived DCs (moDCs)[11, 16, 17]. cDCs patrol the local environment, actively engulf and sample foreign antigens, migrate to the T-cell zones of the draining lymph nodes, and present antigenic peptides to antigen inexperienced/naïve $\mathrm{T}$ cells. pDCs are, particularly, essential for the production of type I interferons and the establishment of anti-viral immunity. On the other hand, moDCs are routinely generated in vitro from monocytes in presence of granulocyte-macrophage colony stimulating factor (GM-CSF, CSF-2) and interleukin4 (IL4) and are often utilized under clinical settings to perform immunotherapies against cancer[17].

Earlier studies unequivocally established the impact of TBI on peripheral immune cells, including both innate (granulocytes and macrophages) and adaptive (T-, B-, and NK- cells) immune system[18-21]. A series of recent studies highlighted the significance of DC-mediated functions during CNS injuries, including TBI[22], middle cerebral artery occlusion and cerebral ischemia[23]. However, physiological consequences of TBI on the development of DCs remain totally unknown. Our previous studies[24-27], as well as of others, established that sustained and chronic inflammation impairs early differentiation pathways in HSCs. In particular, our studies indicated that the Flt $3^{+}$hematopoietic progenitors are more sensitive to acute and chronic inflammation. Based on the key roles of Flt3/Flt3L signaling axis in the differentiation and maintenance of DCs, we hypothesized that TBI-induced inflammation affects differentiation and maintenance of peripheral DCs.

In the present study, we induced experimental TBI in mice and studied its impact on DC maintenance. Our data identified that TBI affects the distribution pattern of DCs and induces an imbalance among DC subsets in both lymphoid and non-lymphoid organs. In addition, the current study demonstrates that TBI results in reduced levels of reactive oxygen species (ROS) in DCs at both early and late phases of TBI, which may explain altered DC differentiation paradigm following TBI. 


\section{Materials and Methods}

Mice and controlled cortical impact injury: Mice were analyzed between 4-12 weeks after birth, unless otherwise specified. C57BL/6 mice were purchased from the Jackson Laboratory. 8-12-week mice were used in this study. After being anesthetized with isoflurane, the subject mice received controlled cortical impact $(\mathrm{CCI})$ using a custom microprocessor-controlled and compressed air driven pneumatic impactor. Briefly, a 10-mm midline incision was made over the skull, the skin and fascia were retracted, and a 4-mm craniotomy was made on the central aspect of the left parietal bone of mice under surgical anesthesia. A moderate injury was induced by a 3.5-mm diameter tip with impact velocity of $6 \mathrm{~m} / \mathrm{s}$ and a deformation depth of $2 \mathrm{~mm}$. In sham mice, same procedure was performed except for the impact. The number of mice in each study is indicated in the figure legends. All surgical procedures and animal experiments were performed under protocols approved by the University of Maryland School of Medicine Institutional Animal Care and Use Committee (IACUC). The surgical procedures were performed by the same investigator using the same equipment. $\mathrm{D}(0.7 \mathrm{mg} / \mathrm{mL})$ and DNase I $(100 \mathrm{U} / \mathrm{mL})$ in RPMI for $45 \mathrm{mins}$ at $37^{\circ} \mathrm{C}$. For skin DC isolation, mouse ears were cut into pieces, digested in the presence of $250 \mathrm{ug} / \mathrm{mL}$ liberase + DNase I $(100 \mathrm{U} / \mathrm{mL})$ in HBSS $+5 \%$ FCS for 90 mins at $37^{\circ} \mathrm{C}$. Cells were vortexed vigorously and passed through a 19-gauge needle to obtain a single cell suspension. Bone marrow cells were isolated from the tibias and femurs by inserting a 23 -gauge needle/ $1 \mathrm{~mL}$ syringe to the bone cavities and flushed with PBS $2 \%$ FCS until the bones become pale. Single cell suspensions were made through rigorous pipetting. Red blood cells were lysed with Ammonium chloride (Stem Cell Technology) and subsequently filtered using a $70 \mu \mathrm{M}$ nylon mesh. Bone marrow cells were then counted with a hemacytometer and trypan blue (Amresco) negative cells were counted as live cells.

Flow cytometry. Cells were analyzed by flow cytometry with Attune Nxt (Thermofisher) and FlowJo software (Tree Star). The following monoclonal antibodies were used: anti- CD34 (RAM34), anti-CD48 (HM48-1), anti-CD117 (2B8), anti-Flt3 (A2F10.1), anti-Sca-1 (D7), anti-B220 (RA3-6B2), anti- CD19 (1D3), anti-CD3 (145-2C11), anti-CD4 (GK1.5), anti-CD8 (53-6.7), anti-CD11b (M1/70), anti- Gr-1 (RB6-8C5), anti-Ter119 (TER119), anti-CD11c (N418), anti-CD8(53-6.7), anti-PDCA1 (129C1), anti-CD24 (M1/69), anti-SIRPa (P84), antiCD103 (2E7), anti-CD45 (S18009F), anti-CD207 (4C7), anti-CD115 (AFS98), anti-LY6C (HK1.4), anti-SiglecH (551), anti-CLEC9A (7H11), anti-CD80 (16-10A1), anti-CD86 (GL-1), anti-CD40(3/23), anti-H2K ${ }^{\mathrm{b}}$ (AF6-88.5), anti-IA/IE (M5/114.15.2) and anti-BrdU (3D4) from Biolegend. Cells incubated with biotinylated monoclonal antibodies were incubated with fluorochrome-conjugated streptavidin-peridinin chlorophyll protein-cyanine 5.5 (551419; BD), streptavidin-allophycocyanin-Cy7 (554063; BD), streptavidin-super bright 650 (Biolegend). In all the FACS plots, indicated are the percentages (\%) of the gated fraction. Data were acquired on a Attune Nxt Acoustic focusing cytometer using Attune software (life technologies) and analyzed using FlowJo (Treestar Inc).

Measuring ROS levels: Single cell suspensions were stained with cell surface markers and then incubated with $2 \mathrm{mM} \mathrm{CM}-\mathrm{H}_{2}$ DCFDA (Life Technologies C6827) in pre-warmed HBSS at $37 \mathrm{C}$ for $15 \mathrm{~min}$. The cells were washed in ice-cold PBS, pelleted and resuspended in ice-cold

191 Statistics. Data represent mean and s.e.m. Significance was evaluated between 2 individual 192 samples using Student unpaired $t$-tests. Comparisons within each surgery group were analyzed 
using two-way ANOVA with multiple comparisons test. For non-parametric data, Mann Whitney test was used $(* \mathrm{P}<0.05, * * \mathrm{P}<0.01, * * *<0.001, * * * *<0.0001)$.

\section{Results}

\section{Augmented DC pool size in the spleen and bone marrow at the acute phase of TBI}

To study if TBI causes alterations in DC compartment, we enumerated the frequencies of DCs in the spleen and BM. Flow cytometry-based immunophenotyping studies indicated reduced relative frequencies, but increased absolute numbers, of $\mathrm{CD} 11 \mathrm{c}^{+} \mathrm{CII}{ }^{+} \mathrm{cDCs}$ in the

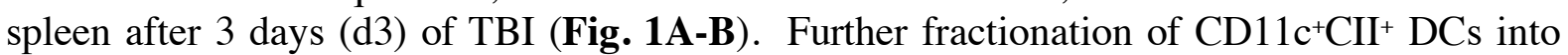
$\mathrm{CD}^{+} \mathrm{CD} 11 \mathrm{~b}^{-}(\mathrm{cDC} 1)$ and $\mathrm{CD} 8 \mathrm{CD} 11 \mathrm{~b}^{+}(\mathrm{cDC} 2)$ subsets[11, 16, 17] subsets revealed; normal relative numbers, but reduced absolute numbers of cDC1 after 1 day (d1) of TBI (Fig. 1C-D); an increase in relative frequencies, normal total frequencies and increased absolute numbers of cDC1 subset after d3 of TBI (Fig. 1C-D); reduced overall frequencies, but increased absolute numbers of cDC2 after d3 of TBI (Fig. 1C, E); and normal relative frequencies, reduced overall frequencies and increased absolute numbers of CD8-CD11b-CD $11 \mathrm{c}^{+} \mathrm{CII}^{+}$immature cDCs in the spleen after d3 of TBI (Fig. 1C-F). Further analysis indicated reduced relative numbers, but increased absolute numbers, of $\mathrm{PDCA}^{+} \mathrm{CD} 11 \mathrm{c}^{\text {int }} \mathrm{pDCs}$ (Fig. 1G-H) and PDCA1 ${ }^{-}$ CD11 $c^{\text {high }}$ cDCs (Fig. 1G, I) in the spleen after d3 of TBI. Interestingly, normal relative frequencies, but reduced absolute numbers, of PDCA1-CD11 $\mathrm{c}^{\text {high }} \mathrm{cDCs}$ was observed in the spleen after d1 of TBI (Fig. 1G, I). Next, we determined the frequencies of DCs in the BM and analysis revealed an increase in both relative frequencies and absolute numbers of PDCA $1{ }^{+} \mathrm{CD} 11 \mathrm{c}^{\text {int }}$ pDCs in the BM after $\mathrm{d} 1$ and $\mathrm{d} 3$ of TBI (Fig. 1J-K). On the other hand, frequencies of $\mathrm{CD} 11 \mathrm{c}^{+} \mathrm{CII}{ }^{+} \mathrm{cDCs}$ were reduced, even though their absolute numbers were normal, in the BM after d3 of TBI (Fig. 1L-M). Finally, absolute numbers of $\mathrm{CD} 11 \mathrm{c}^{+} \mathrm{CII}^{+}$ cDCs were increased, while the relative numbers were normal, in the BM after $\mathrm{d} 1$ of TBI (Fig. 1L-M). Overall, these data indicate that the frequencies and absolute numbers of DCs in the spleen and BM are altered at the acute phase of TBI.

\section{Altered DC subsets in the spleen and BM at the late phase of TBI}

To investigate the impact of TBI on DC subsets at the later phases, we performed immunophenotyping studies after 7 days (d7) of TBI. Our studies indicated normal frequencies, but increased absolute numbers, of $\mathrm{CD} 11 \mathrm{c}^{+} \mathrm{CII}{ }^{+} \mathrm{cDCs}$ in the spleen of $\mathrm{d} 7 \mathrm{TBI}$ mice (Fig. 2A). Further analysis of splenic cDC fraction of d7 TBI mice indicated; increased frequencies and absolute numbers of $\mathrm{cDC} 1$ subset (Fig. 2B); reduced frequencies, but normal absolute numbers, of cDC2 subset (Fig. 2C); and reduced frequencies, but normal absolute numbers, of immature cDC subset (Fig. 2D). Analysis of pDC compartment indicated increased frequencies and absolute numbers in spleen of d7 TBI mice (Fig. 2E). Consistent with data shown in Fig. 2A, frequencies of PDCA1-CD11 $\mathrm{c}^{\text {high }}$ were normal, but their absolute numbers were augmented in the spleen of d7 TBI mice (Fig. 2F).

On the other hand, analysis of DC subsets in the BM of d7 TBI mice revealed; a remarkable decrease in both frequencies and absolute numbers of $\mathrm{CD} 11 \mathrm{c}^{+} \mathrm{CII}{ }^{+} \mathrm{cDCs}(\mathbf{F i g} .2 \mathrm{G})$; reduced frequencies and absolute numbers of $\mathrm{cDC1}$ (Fig. 2H); non-significant reduction in relative frequencies, but a reduction in absolute numbers, of cDC2 (Fig. 2I); decreased relative frequencies and absolute numbers of pDCs (Fig. 2J); and reduced frequencies and absolute numbers of PDCA1-CD11 chigh $\mathrm{cDCs}$ (Fig. 2K). In essence, these data specify that later phases of TBI induces an imbalance in the distribution of $\mathrm{cDC}$ and $\mathrm{pDC}$ subsets in the spleen and BM.

\section{TBI alters expression levels of surface markers involved in DC functions}

To test if expression of surface antigens essential for DC functions is affected by TBI, we performed detailed immunophenotyping studies. Analysis indicated CD80 expression was 
normal in total DCs, cDC1 and cDC2 subsets of the spleen after d1 and d3 of TBI (Fig. 3A). However, CD80 expression was modestly reduced in splenic pDCs after d3, when compared with d1, of TBI (Fig. 3A). Expression of CD86 was increased on total DCs and CDC2 subset on d1, when compared with that of d3 after TBI (Fig. 3B). Interestingly, CD86 expression levels in $\mathrm{cDC} 1$ subset were reduced on $\mathrm{d} 3$ after TBI and in pDCs remain unchanged after TBI (Fig. 3B). More importantly, expression levels of MHC class I (Fig. 3C) and MHC class II (Fig. 3D) were normal in total DCs, cDC1, cDC2 and pDCs of spleen after d1 and d3 of TBI. Next, we assessed if DC associated surface markers are altered at the late phase of TBI. Analysis on expression levels of surface antigen in splenic DC subsets of d7 TBI mice revealed; normal expression levels of CD80 in cDC, $\mathrm{CDC} 1, \mathrm{cDC} 2$ and pDC subsets (Fig. 3E); increased expression levels of CD86 in total $\mathrm{cDC}, \mathrm{cDC} 1$ and $\mathrm{cDC} 2$ subsets, whereas normal levels of CD86 in pDCs (Fig. 3F); and reduced MHC-CII expression in total cDC, cDC1 and cDC2 subsets, whereas normal levels of MHC-CII in pDCs (Fig. 3G). Immunophenotyping studies on BM DC subsets of d7 TBI mice indicated decreased MHC-CII and CD86 expression, whereas normal CD80 expression, in pDC subset (Fig. 3H) and striking reduction of MHC-CII and CD86 expression, whereas increased levels of CD80 expression, in PDCA1$\mathrm{CD} 11 \mathrm{C}^{+} \mathrm{cDC}$ fraction (Fig. 3I). Overall, these data indicate that TBI affects surface expression of molecules involved in antigen presentation of DCs at both early and late phases of injury.

\section{TBI causes an imbalance in DCs subsets within the circulatory and lymphatic systems}

Under steady state conditions DCs are constantly circulated throughout the body to perform immune surveillance and distributed to different organs through sophisticated networks of the blood and lymphatic systems[8-12]. To study if TBI has an impact on circulating DCs, we determined their frequencies in the blood and lymph nodes. Analysis of peripheral blood indicated normal frequencies of total cDCs (Fig. 4A). However, within cDCs, a remarkable increase of $\mathrm{cDC} 1$ and a decrease of $\mathrm{cDC} 2$ subsets were observed in $\mathrm{d} 7 \mathrm{TBI}$ mice (Fig. 4A). Interestingly, expression levels of MHC-CII were increased in total cDCs of blood from d7 TBI mice and further analysis indicated that this increase was specific to the cDC1, but not to the cDC2, compartment (Fig. 4B). Next, we investigated the frequencies of DCs in the skin draining/peripheral lymph nodes (pLN). Analysis indicated normal frequencies of total cDCs and pDCs in the pLNs from d7 TBI mice (Fig. 4C). However, determination of cDC subsets revealed a remarkable decrease of $\mathrm{cDC} 1$ and increase of $\mathrm{cDC} 2$ subsets in the pLNs of d7 TBI mice (Fig. 4C). Interestingly, immunophenotyping studies on pLN DCs from d7 TBI mice indicated; a striking decrease of MHC- CII expression in all DC subsets, including total cDC, cDC1, cDC2 and pDC subsets (Fig. 4D, left); normal expression levels of CD80 in total cDCs and pDCs. However, within cDCs, CD80 was decreased in $\mathrm{CDC} 1$ and increased in cDC2 subsets (Fig. 4D, middle); and CD86 expression was remarkably reduced in total cDC, cDC1 and pDC subsets, even though CD86 expression was normal in cDC2 subset (Fig. 4D, right). Finally, we analyzed the DC compartments in the mesenteric lymph nodes (mLNs) and the data indicated that the frequencies of total cDCs were decreased in d7 TBI mice (Fig. 4E). However, within cDCs, there was a relative increase of cDC1 subset and a decrease in cDC2 subset in the mLNs of d7 TBI mice (Fig. 4E). Immunophenotyping studies on mLN cDCs from d7 TBI mice suggested; normal expression levels of MHC-CII in total cDC, cDC1 and cDC2 subsets (Fig. 4F, left); increased expression levels of CD80 expression in cDC, cDC1 and cDC2 subsets (Fig. 4F, middle); and remarkable upregulation of CD86 in cDC, cDC1 and cDC2 subsets (Fig. 4F, right). Taken together these data demonstrate that TBI affects distribution and functions of specific DC subsets of both circulatory and lymphatic systems.

\section{TBI affects distribution of DC subsets within solid organs}


DC subsets of the solid organs, including lungs, liver and skin, participate in active immune surveillance and maintaining a proper balance of $\mathrm{cDC} 1, \mathrm{cDC} 2$ and $\mathrm{pDC}$ subsets is vital for their functions[11, 17, 28, 29]. Emerging studies demonstrate that both non-lymphoid and lymphoid tissue DCs derive from the same precursors in the BM[11] and follow a related differentiation program[30, 31]. To test if TBI impacts the DC composition of solid organs, we determined the frequencies of DC compartments of the lungs. Frequencies of total $\mathrm{CD} 11 \mathrm{c}^{+} \mathrm{CII}^{+} \mathrm{cDC}$ s were increased within the $\mathrm{CD} 45^{+}$hematopoietic fraction of lungs from $\mathrm{d} 7$ TBI mice (Fig. 5A). However, within $\mathrm{CD}_{4} 5^{+} \mathrm{CD} 11 \mathrm{c}^{+} \mathrm{CII}{ }^{+} \mathrm{cDCs}$, frequencies of $\mathrm{CD} 103^{+} \mathrm{cDC} 1$ subset were increased and $\mathrm{CD} 11 \mathrm{~b}^{+} \mathrm{cDC} 2$ subset was normal in the lungs of $\mathrm{d} 7 \mathrm{TBI}$ mice (Fig. 5B). Further analysis of $\mathrm{CD} 45^{+} \mathrm{CD} 11 \mathrm{c}^{+} \mathrm{CII}{ }^{+} \mathrm{CD} 11 \mathrm{~b}^{+} \mathrm{cDC} 2$ fraction revealed a decrease of $\mathrm{CD} 4{ }^{+}$ cDC2 subset and normal frequencies of CD4 ${ }^{-} \mathrm{cDC} 2$ in the lungs of $\mathrm{d} 7 \mathrm{TBI}$ mice (Fig. 5C). Frequencies of $\mathrm{CD} 45^{+} \mathrm{CD} 11 \mathrm{c}^{+} \mathrm{CII}{ }^{+} \mathrm{PDCA} 1^{+} \mathrm{pDCs}$ were reduced in the lungs of $\mathrm{d} 7 \mathrm{TBI}$ mice (Fig. 5D).

Next, we analyzed the DCs of liver from d7 TBI mice. Frequencies of CD11 $\mathrm{c}^{+} \mathrm{CII}^{+}$ cDCs within $\mathrm{CD}^{4} 5^{+}$fraction were elevated in the liver of d7 TBI mice (Fig. 5E). However, within $\mathrm{CD}_{4} 5^{+} \mathrm{CD} 11 \mathrm{c}^{+} \mathrm{CII}{ }^{+} \mathrm{cDCs}$, frequencies of $\mathrm{CD} 103^{+} \mathrm{cDC} 1$ subset were increased and $\mathrm{CD}_{11 b^{+}}$cDC2 subset was normal in the liver of $\mathrm{d} 7 \mathrm{TBI}$ mice (Fig. 5F). Further analysis of $\mathrm{CD} 45^{+} \mathrm{CD} 11 \mathrm{c}^{+} \mathrm{CII}{ }^{+} \mathrm{CD} 11 \mathrm{~b}^{+} \mathrm{cDC} 2$ fraction revealed an increase of $\mathrm{CD}^{+} \mathrm{cDC} 2$ subset and normal frequencies of CD4 ${ }^{-} \mathrm{CDC} 2$ in the liver of d7 TBI mice (Fig. 5G). Frequencies of $\mathrm{CD} 45^{+} \mathrm{CD} 11 \mathrm{c}^{+} \mathrm{CII}{ }^{+} \mathrm{PDCA}^{+} \mathrm{pDCs}$ were elevated in the liver of $\mathrm{d} 7 \mathrm{TBI}$ mice (Fig. 5H). Immunophenotyping studies indicated reduced expression levels of MHC-CII in total cDC, cDC1 and $\mathrm{CDC} 2$ subsets, whereas normal expression levels of MHC-CII in pDCs from the liver of d7 TBI mice (Fig. 5I).

Finally, we determined the frequencies of DCs in the skin. Frequencies of total CD45+ hematopoietic cells were increased in the skin of d7 TBI mice (Fig. 5J). However, within $\mathrm{CD} 45^{+}$fraction, the frequencies of $\mathrm{CD} 11 \mathrm{c}^{+} \mathrm{CII}^{+} \mathrm{DCs}$ were reduced in the skin of $\mathrm{d} 7 \mathrm{TBI}$ mice (Fig. 5K). Determination of CD $11 \mathrm{c}^{+} \mathrm{CII}^{+} \mathrm{CD} 103^{+} \mathrm{CD} 207^{+}$dermal DCs and $\mathrm{CD} 11 \mathrm{c}^{+} \mathrm{CII}^{+} \mathrm{CD} 103^{-}$ CD207+ Langerhans Cells (LCs) indicated a reduction of both fractions in the skin of d7 TBI mice (Fig. 5L-M). Overall, these data indicate that TBI impacts the distribution and composition of DC subsets within the solid organs that participate in immune-surveillance functions.

\section{TBI affects early differentiation pathways of DCs in the BM}

Early stages of DC differentiation occur in the BM through commitment of hematopoietic stem cells (HSCs) to common dendritic cell progenitors (CDPs)[32]. Indeed, changes in the frequencies and numbers of CDPs result in abnormal composition of DCs in both lymphoid and non-lymphoid organs[11, 16, 17]. In view of the fact that TBI affects distribution of DCs in almost all organs, we investigated if TBI has an impact on the early stages of DC differentiation. Flow cytometric analyses identified reduced relative frequencies of Linc-Kit ${ }^{\text {int }} \mathrm{Flt} 3{ }^{+} \mathrm{CD} 115^{+}$CDPs in the BM of d1 and d3 TBI mice (Fig. 6A-B), decreased overall frequencies of CDPs in the BM of d3 TBI mice (Fig. 6A,C), and diminished absolute numbers of CDPs in the BM of d3 TBI mice (Fig. 6A,D). On the other hand, relative frequencies (Fig. 6A, E), overall frequencies (Fig. 6A, F), and absolute numbers (Fig. 6A, G) of Linc-Kit ${ }^{\text {intFlt }}{ }^{+}{ }^{+} \mathrm{CD} 115^{-}$pDC-committed-progenitors were augmented in the BM of both $\mathrm{d} 1$ and $\mathrm{d} 3 \mathrm{TBI}$ mice. To study if these changes in the DC progenitors of the BM are consistent at the later phase of TBI, we analyzed the BM of d7 TBI mice. Interestingly, our data on CDPs indicated that the relative frequencies were normal $($ Fig. $6 \mathbf{H})$, overall frequencies were

339 increased (Fig. 6I), and the absolute numbers (Fig. 6J) were augmented in the BM of d7 TBI 340 mice. However, the relative frequencies (Fig. 6K), overall frequencies (Fig. 6L), and absolute 
numbers (Fig. 6M) remain normal in the BM of d7 TBI mice. These data demonstrate that TBI affects early differentiation program of DCs, especially at the stages of commitment to CDPs.

\section{Discussion}

372

\section{TBI suppresses Reactive Oxygen Species production in DC- subsets and progenitors}

One of the hallmark features of secondary injury following TBI is augmented levels of ROS and oxidative stress in innate immune cells, including microglia and macrophages[33, 34]. Of note, ROS have been shown to play critical and decisive roles at the early differentiation stages of human and mouse DCs in the BM[35-39]. In an attempt to understand the molecular mechanisms that could contribute to altered DC differentiation at early and late phases of TBI, we determined the expression levels of ROS in DC subsets and progenitors. Intriguingly, our analysis indicated reduced frequencies of ROS $^{\text {high }}$ and total intracellular ROS levels in cDCs of spleen on $\mathrm{d} 1$ and $\mathrm{d} 3$ after TBI (Fig. 7A, B). Further analysis of cDC subsets revealed a reduction in the frequency of ROS ${ }^{\text {high }}$ splenic $\mathrm{cDC} 1$ subset from $\mathrm{d} 1 \mathrm{TBI}$ mice (Fig. 7C, D), and a decrease in both frequencies of ROS ${ }^{\text {high }}$ and total intracellular ROS levels in splenic cDC2 subset from d1 and d3 TBI mice (Fig. 7E, F). Consistently, analysis of CD8-CD11 b- immature cDCs exhibited reduced frequencies of ROS ${ }^{\text {high }}$ cells and total intracellular ROS levels from d1 and d3 TBI mice (Fig. 7G, H). On the other hand, ROS levels in pDCs indicated normal frequencies of $\operatorname{ROS}^{\text {high }}$ pDCs from $\mathrm{d} 1$ and $\mathrm{d} 3 \mathrm{TBI}$ mice and a reduction in total intracellular ROS levels in pDCs from d3 TBI mice (Fig. 7I, J). To assess the alterations in ROS levels in DC subsets at late phase of TBI, we studied DCs from d7 TBI mice. Our data concluded that the total intracellular ROS levels were remarkably reduced in total cDC (Fig. 7K), cDC1 (Fig. 7L), cDC2 (Fig. 7M), immature cDC (Fig. 7N) and pDC (Fig. 7O) subsets from the spleen of d7 TBI mice. Finally, we determined if ROS levels are altered at the early development stages of DCs following TBI. Analysis indicated that both frequencies of ROS ${ }^{\text {high }}$ CDPs and total intracellular ROS levels in CDPs were reduced in the BM of $\mathrm{d} 1$ and $\mathrm{d} 3 \mathrm{TBI}$ mice (Fig. 7P). In essence, these data established that the intracellular ROS levels were reduced in DC progenitors and differentiated DCs at both early and late phases of TBI.

Infections are a leading cause of morbidity and mortality in patients with acute CNS injury, such as TBI, stroke and spinal cord injury[19-21, 40]. Indeed, there exists a direct correlation between infections and poorer clinical outcomes overall[41]. More importantly, infections were found to be the key driver of $\sim 19 \%$ of mortality in TBI patients, that survived at least one year after TBI[42]. Mounting evidences indicate that nosocomial infections (following TBI) are major contributors of not only to mortality, but also inducers of deleterious long-term consequences in patients[43]. Furthermore, infections acquired after TBI may trigger pathophysiological sequelae and exacerbate neurodegeneration[44, 45], intracranial hypertension and an associated need for longer duration on mechanical ventilation[46-50]. Indeed, survivors of brain trauma are 2.3-4.3 times more likely to die than general population, with increased risk of death from pneumonia or sepsis[42]. Recent studies indicated that up to $75 \%$ of severe TBI patients have been reported to develop sepsis, that itself is linked to high rates of morbidity, cognitive impairment, anxiety and depression, mediated multi-organ failure[51]. Post-traumatic immune insults are life-threatening complications in patients with moderate-severe TBI and observed in up to $55 \%$ of patients[51]. The most common nosocomial infections in TBI patients include, pneumonia/lower respiratory tract infections, urinary tract infections and surgical site infections[19, 20, 51-53]. Given the fact that resistance 
to all of these infections is dependent on a functional immune system, providing and/or preserving competent and functional immune components would be a reasonable and effective therapeutic strategy to treat TBI patients.

DCs are regarded as the most professional antigen presenting cells and indispensable in initiating T-, B- and NK- cell mediated adaptive immune responses against viral, fungal and bacterial infections[9-12]. In particular, DCs are essential to provide immunity against lung infections, including viral and bacterial pneumonia[28, 54-58]. Intriguingly, our data from this current study document that TBI directly affects the pool and composition of DCs in almost all lymphoid and non-lymphoid organs, including lungs. These altered frequencies and numbers of $\mathrm{cDC} 1, \mathrm{cDC} 2$ and $\mathrm{pDCs}$ subsets in each tissue may be, at least in part, responsible for the immune dysfunction caused by TBI. More importantly, our analyses concluded that TBI affects the immunogenicity of DCs, such as altered surface expression of MHC CI and CII proteins and co-stimulatory molecules- CD80 and CD86, which may eventually lead to defective functions of DCs.

Mounting evidences established that TBI affects organs outside the CNS. Mirzayan et al. reported that TBI causes augmented migration and infiltration of immune cells to peripheral organs, such as lungs and liver, which eventually led to histopathological changes and various degrees of organ dysfunction[59]. Interestingly, their study concluded that the composition of spleen and kidney were not altered in response to TBI. On the other hand, a series of studies established that peripheral immune cells play a critical role in the overall pathology after brain injury. Indeed, splenectomy in rats immediately after TBI resulted in decreased expression of pro-inflammatory cytokines, mortality rate, improved cognitive function[60] and attenuated neurodegeneration and CCL20 chemokine expression in the brain[18]. Most of the peripheral innate immune cells, including neutrophils, monocytes and macrophages, are believed to respond at the early phase and decline within few days after TBI[61]. Intriguingly, our present data suggest that peripheral DC composition and numbers are altered within 24 hours of TBI and exhibited sustained changes even after 7 days of TBI. However, it is unclear, at present, if peripheral DCs migrate to the injured site in the brain and participate in inflammation and neurodegeneration. Future studies with an in-depth focus on identifying the involvement of DCs in neuroinflammation and pathophysiology of CNS would be essential.

Emerging studies have unequivocally established the contribution of oxidative stress to secondary injury in TBI pathology, including development of cerebral edema, inflammation, and the secondary neuronal damage found post-TBI. Disrupted blood flow after TBI leads to cerebral hypoxia or ischemia with the consequent decrease of oxygen and glucose supply to the CNS[62]. In addition, mitochondrial dysfunction caused by TBI results in marked accumulation of ROS in the brain[63]. In sharp contrast, our studies identified that ROS levels were rather diminished in both differentiated DCs and DC subsets at early and late phases of TBI. In keeping with our findings, neutrophil ROS production in patients with moderate or severe TBI was significantly lower than that of healthy age- and sex- matched individuals[61]. Given the importance of ROS in the differentiation and functional integrity of DCs[35-39], we speculate that impaired ROS generation might be responsible for DC alterations in peripheral organs after TBI. At present, it is unclear as if TBI is either directly or indirectly responsible for the ROS defects in DCs. In addition, mechanisms that are responsible for reduced ROS in DCs after TBI need to be elucidated. 
While a great deal of research has been devoted to deciphering the relationship between brain trauma and peripheral immune system, very little is known regarding precise mechanisms through which interactions between peripheral lymphoid organs and CNS are regulated. Neuronal and hormonal mechanisms, such as the cholinergic anti-inflammatory pathway, the adrenergic pathway and the hypothalamic pituitary axis (HPA), have been postulated to play crucial roles in regulating the peripheral immune response following CNS injury[20, 64-66]. Interestingly, most of these studies have focused on brain-spleen crosstalk following CNS injury $[65,67]$. It is unclear if such neuronal and hormonal mechanisms play any roles in the early differentiation pathways of immune cells in BM following TBI. In the present study, we establish that the alterations of DCs in the peripheral lymphoid organs, including spleen, are associated with increased differentiation of CDPs in the BM. Of note, TBI induced inflammatory response is not confined to the brain and can cause a systemic inflammatory response syndrome (SIRS), including elevated levels of TNF $\alpha$, IL1 $\beta$ and IL6 in the blood serum[68-71]. Recent studies, including our own[24-27, 72], demonstrated that exaggerated expression of inflammatory cytokines, such as TNF $\alpha$, IL1 $\beta$, IFN $\alpha$, IFN $\gamma$, and IL6, affects early differentiation of immune cells[73-75]. Based on these studies, it is tempting to speculate that exaggerated pro-inflammatory signals might be responsible, at least in part, for increased early differentiation of DCs in the BM after TBI. However, the involvement of additional mechanisms, including neuronal and hormonal control, in the differentiation and maintenance DCs after CNS injury cannot be underestimated and awaits further investigation. A deeper understanding on the molecular mechanisms that contribute to DC defects following TBI would be essential and beneficial in treating infections in patients with acute central nervous system (CNS) injuries, such as TBI, stroke and spinal cord injury.

\title{
Conclusion
}

Our data demonstrate, for the first time, that TBI affects the distribution pattern of DCs and induces an imbalance among DC subsets in both lymphoid and non-lymphoid organs. In addition, the current study demonstrates that TBI results in reduced levels of ROS in DCs at both early and late phases of TBI, which may explain altered DC differentiation paradigm following TBI. A deeper understanding on the molecular mechanisms that contribute to DC defects following TBI would be essential and beneficial in treating infections in patients with acute CNS injuries, such as TBI, stroke and spinal cord injury.

\section{Availability of data and materials}

The data that support the findings of this study are available from corresponding author on reasonable request.

\section{Abbreviations}

\section{TBI: Traumatic Brain Injury}

\section{DC: Dendritic Cells}

\section{CDP: Common Dendritic Cell Progenitor}

\author{
pDC-P: plasmacytoid DC Progenitor
}


cDCs: conventional or classical DCs

pDCs: plasmacytoid DCs

491

CNS: Central Nervous System

493

ROS: Reactive Oxygen Species

495

BM: Bone Marrow

497

498

499

500

501

502

503

504

Consent to participate:

505

Not applicable

pLN: peripheral lymph node

mLN: peripheral lymph node

\section{Acknowledgements}

510 Not applicable

\section{References}

1. Jassam YN, Izzy S, Whalen M, McGavern DB, El Khoury J: Neuroimmunology of

2. Maas AI, Stocchetti N, Bullock R: Moderate and severe traumatic brain injury in adults. Lancet Neurol 2008, 7:728-741.

3. Langlois JA, Rutland-Brown W, Wald MM: The epidemiology and impact of traumatic brain injury: a brief overview. J Head Trauma Rehabil 2006, 21:375378.

4. Nguyen R, Fiest KM, McChesney J, Kwon CS, Jette N, Frolkis AD, Atta C, Mah S, Dhaliwal H, Reid A, et al: The International Incidence of Traumatic Brain Injury: A Systematic Review and Meta-Analysis. Can J Neurol Sci 2016, 43:774785.

5. Roozenbeek B, Maas AI, Menon DK: Changing patterns in the epidemiology of traumatic brain injury. Nat Rev Neurol 2013, 9:231-236.

6. Skolnick BE, Maas AI, Narayan RK, van der Hoop RG, MacAllister T, Ward JD, Nelson NR, Stocchetti N, Investigators ST: A clinical trial of progesterone for severe traumatic brain injury. N Engl J Med 2014, 371:2467-2476. 
7. Bramlett HM, Dietrich WD: Long-Term Consequences of Traumatic Brain

8. Ganguly D, Haak S, Sisirak V, Reizis B: The role of dendritic cells in autoimmunity. Nat Rev Immunol 2013, 13:566-577.

9. Steinman RM: Decisions about dendritic cells: past, present, and future. Annu Rev Immunol 2012, 30:1-22.

10. Belz GT, Nutt SL: Transcriptional programming of the dendritic cell network. Nat Rev Immunol 2012, 12:101-113.

11. Merad M, Sathe P, Helft J, Miller J, Mortha A: The dendritic cell lineage: ontogeny and function of dendritic cells and their subsets in the steady state and the inflamed setting. Annu Rev Immunol 2013, 31:563-604.

12. Miller JC, Brown BD, Shay T, Gautier EL, Jojic V, Cohain A, Pandey G, Leboeuf M, Elpek KG, Helft J, et al: Deciphering the transcriptional network of the dendritic cell lineage. Nat Immunol 2012, 13:888-899.

13. Bigley V, Haniffa M, Doulatov S, Wang XN, Dickinson R, McGovern N, Jardine L, Pagan S, Dimmick I, Chua I, et al: The human syndrome of dendritic cell, monocyte, B and NK lymphoid deficiency. $J$ Exp Med 2011, 208:227-234.

14. Dickinson RE, Griffin H, Bigley V, Reynard LN, Hussain R, Haniffa M, Lakey JH, Rahman T, Wang XN, McGovern N, et al: Exome sequencing identifies GATA-2 mutation as the cause of dendritic cell, monocyte, $B$ and NK lymphoid deficiency. Blood 2011, 118:2656-2658.

15. Hambleton S, Salem S, Bustamante J, Bigley V, Boisson-Dupuis S, Azevedo J, Fortin A, Haniffa M, Ceron-Gutierrez L, Bacon CM, et al: IRF8 mutations and human dendritic-cell immunodeficiency. $N$ Engl J Med 2011, 365:127-138.

16. Mildner A, Jung S: Development and function of dendritic cell subsets. Immunity 2014, 40:642-656.

17. Sichien D, Lambrecht BN, Guilliams M, Scott CL: Development of conventional dendritic cells: from common bone marrow progenitors to multiple subsets in peripheral tissues. Mucosal Immunol 2017, 10:831-844.

18. Das M, Leonardo CC, Rangooni S, Pennypacker KR, Mohapatra S, Mohapatra SS: Lateral fluid percussion injury of the brain induces CCL20 inflammatory chemokine expression in rats. $J$ Neuroinflammation 2011, 8:148.

19. Faden AI, Barrett JP, Stoica BA, Henry RJ: Bidirectional Brain-Systemic Interactions and Outcomes After TBI. Trends Neurosci 2021, 44:406-418.

20. Meisel C, Schwab JM, Prass K, Meisel A, Dirnagl U: Central nervous system injury-induced immune deficiency syndrome. Nat Rev Neurosci 2005, 6:775-786.

21. Sharma R, Shultz SR, Robinson MJ, Belli A, Hibbs ML, O'Brien TJ, Semple BD: Infections after a traumatic brain injury: The complex interplay between the immune and neurological systems. Brain Behav Immun 2019, 79:63-74.

22. Israelsson C, Kylberg A, Bengtsson H, Hillered L, Ebendal T: Interacting chemokine signals regulate dendritic cells in acute brain injury. PLoS One 2014, 9:e104754.

23. Gallizioli M, Miro-Mur F, Otxoa-de-Amezaga A, Cugota R, Salas-Perdomo A, Justicia C, Brait VH, Ruiz-Jaen F, Arbaizar-Rovirosa M, Pedragosa J, et al: Dendritic Cells and Microglia Have Non-redundant Functions in the Inflamed Brain with Protective Effects of Type 1 cDCs. Cell Rep 2020, 33:108291.

24. Nakagawa MM, Chen H, Rathinam CV: Constitutive Activation of NF-kappaB Pathway in Hematopoietic Stem Cells Causes Loss of Quiescence and Deregulated Transcription Factor Networks. Front Cell Dev Biol 2018, 6:143. 
25. Nakagawa MM, Davis H, Rathinam CV: A20 deficiency in multipotent progenitors perturbs quiescence of hematopoietic stem cells. Stem Cell Res 2018, 33:199-205.

26. Nakagawa MM, Rathinam CV: Constitutive Activation of the Canonical NFkappaB Pathway Leads to Bone Marrow Failure and Induction of Erythroid Signature in Hematopoietic Stem Cells. Cell Rep 2018, 25:2094-2109 e2094.

27. Nakagawa MM, Thummar K, Mandelbaum J, Pasqualucci L, Rathinam CV: Lack of the ubiquitin-editing enzyme A20 results in loss of hematopoietic stem cell quiescence. $J$ Exp Med 2015, 212:203-216.

28. Eddy WE, Gong KQ, Bell B, Parks WC, Ziegler SF, Manicone AM: Stat5 Is Required for CD103(+) Dendritic Cell and Alveolar Macrophage Development and Protection from Lung Injury. J Immunol 2017, 198:4813-4822.

29. Guilliams M, Lambrecht BN, Hammad H: Division of labor between lung dendritic cells and macrophages in the defense against pulmonary infections. Mucosal Immunol 2013, 6:464-473.

30. Ginhoux F, Liu K, Helft J, Bogunovic M, Greter M, Hashimoto D, Price J, Yin N, Bromberg J, Lira SA, et al: The origin and development of nonlymphoid tissue CD103+ DCs. $J$ Exp Med 2009, 206:3115-3130.

31. Helft J, Ginhoux F, Bogunovic M, Merad M: Origin and functional heterogeneity of non-lymphoid tissue dendritic cells in mice. Immunol Rev 2010, 234:55-75.

32. Onai N, Obata-Onai A, Schmid MA, Ohteki T, Jarrossay D, Manz MG: Identification of clonogenic common Flt3+M-CSFR+ plasmacytoid and conventional dendritic cell progenitors in mouse bone marrow. Nat Immunol 2007, 8:1207-1216.

33. Hall ED, Wang JA, Miller DM: Relationship of nitric oxide synthase induction to peroxynitrite-mediated oxidative damage during the first week after experimental traumatic brain injury. Exp Neurol 2012, 238:176-182.

34. Kumar A, Barrett JP, Alvarez-Croda DM, Stoica BA, Faden AI, Loane DJ: NOX2 drives M1-like microglial/macrophage activation and neurodegeneration following experimental traumatic brain injury. Brain Behav Immun 2016, 58:291309.

35. Del Prete A, Zaccagnino P, Di Paola M, Saltarella M, Oliveros Celis C, Nico B, Santoro $\mathrm{G}$, Lorusso $\mathrm{M}$ : Role of mitochondria and reactive oxygen species in dendritic cell differentiation and functions. Free Radic Biol Med 2008, 44:14431451.

36. Sattler M, Winkler T, Verma S, Byrne CH, Shrikhande G, Salgia R, Griffin JD: Hematopoietic growth factors signal through the formation of reactive oxygen species. Blood 1999, 93:2928-2935.

37. Sheng KC, Pietersz GA, Tang CK, Ramsland PA, Apostolopoulos V: Reactive oxygen species level defines two functionally distinctive stages of inflammatory dendritic cell development from mouse bone marrow. J Immunol 2010, 184:28632872.

38. Sinha A, Singh A, Satchidanandam V, Natarajan K: Impaired generation of reactive oxygen species during differentiation of dendritic cells (DCs) by Mycobacterium tuberculosis secretory antigen (MTSA) and subsequent activation of MTSA-DCs by mycobacteria results in increased intracellular survival. J Immunol 2006, 177:468-478.

39. Zaccagnino P, Saltarella M, Maiorano S, Gaballo A, Santoro G, Nico B, Lorusso M, Del Prete A: An active mitochondrial biogenesis occurs during dendritic cell differentiation. Int J Biochem Cell Biol 2012, 44:1962-1969. 
40. Iadecola C, Anrather J: The immunology of stroke: from mechanisms to translation. Nat Med 2011, 17:796-808.

41. Kesinger MR, Kumar RG, Wagner AK, Puyana JC, Peitzman AP, Billiar TR, Sperry $\mathrm{JL}$ : Hospital-acquired pneumonia is an independent predictor of poor global outcome in severe traumatic brain injury up to 5 years after discharge. $J$ Trauma Acute Care Surg 2015, 78:396-402.

42. Harrison-Felix C, Kolakowsky-Hayner SA, Hammond FM, Wang R, Englander J, Dams-O'Connor K, Kreider SE, Novack TA, Diaz-Arrastia R: Mortality after surviving traumatic brain injury: risks based on age groups. $J$ Head Trauma Rehabil 2012, 27:E45-56.

43. Andraweera N, Seemann R: Acute rehospitalisation during the first 3 months of in-patient rehabilitation for traumatic brain injury. Aust Health Rev 2016, 40:114-117.

44. Failli V, Kopp MA, Gericke C, Martus P, Klingbeil S, Brommer B, Laginha I, Chen Y, DeVivo MJ, Dirnagl U, Schwab JM: Functional neurological recovery after spinal cord injury is impaired in patients with infections. Brain 2012, 135:32383250.

45. Perry VH, Newman TA, Cunningham C: The impact of systemic infection on the progression of neurodegenerative disease. Nat Rev Neurosci 2003, 4:103-112.

46. Bronchard R, Albaladejo P, Brezac G, Geffroy A, Seince PF, Morris W, Branger C, Marty J: Early onset pneumonia: risk factors and consequences in head trauma patients. Anesthesiology 2004, 100:234-239.

47. Esnault P, Nguyen C, Bordes J, D'Aranda E, Montcriol A, Contargyris C, Cotte J, Goutorbe P, Joubert C, Dagain A, et al: Early-Onset Ventilator-Associated Pneumonia in Patients with Severe Traumatic Brain Injury: Incidence, Risk Factors, and Consequences in Cerebral Oxygenation and Outcome. Neurocrit Care 2017, 27:187-198.

48. Jovanovic B, Milan Z, Djuric O, Markovic-Denic L, Karamarkovic A, Gregoric P, Doklestic K, Avramovic J, Velickovic J, Bumbasirevic V: Twenty-Eight-Day Mortality of Blunt Traumatic Brain Injury and Co-Injuries Requiring Mechanical Ventilation. Med Princ Pract 2016, 25:435-441.

49. Magnotti LJ, Croce MA, Fabian TC: Is ventilator-associated pneumonia in trauma patients an epiphenomenon or a cause of death? Surg Infect (Larchmt) 2004, 5:237-242.

50. Safdar N, Dezfulian C, Collard HR, Saint S: Clinical and economic consequences of ventilator-associated pneumonia: a systematic review. Crit Care Med 2005, 33:2184-2193.

51. McDonald SJ, Sharkey JM, Sun M, Kaukas LM, Shultz SR, Turner RJ, Leonard AV, Brady RD, Corrigan F: Beyond the Brain: Peripheral Interactions after Traumatic Brain Injury. J Neurotrauma 2020, 37:770-781.

52. Das M, Mohapatra S, Mohapatra SS: New perspectives on central and peripheral immune responses to acute traumatic brain injury. $J$ Neuroinflammation 2012 , 9:236.

53. Hazeldine J, Lord JM, Belli A: Traumatic Brain Injury and Peripheral Immune Suppression: Primer and Prospectus. Front Neurol 2015, 6:235.

54. Beshara R, Sencio V, Soulard D, Barthelemy A, Fontaine J, Pinteau T, Deruyter L, Ismail MB, Paget C, Sirard JC, et al: Alteration of Flt3-Ligand-dependent de novo generation of conventional dendritic cells during influenza infection contributes to respiratory bacterial superinfection. PLoS Pathog 2018, 14:e1007360. 
683

684

685

686

687

688

689

690

691

692

693

694

695

696

697

698

699

700

701

702

703

704

705

706

707

708

709

710

711

712

713

714

715

716

717

718

719

720

721

722

723

724

725

726

727

728

729

730

731

55. GeurtsvanKessel CH, Willart MA, van Rijt LS, Muskens F, Kool M, Baas C, Thielemans K, Bennett C, Clausen BE, Hoogsteden HC, et al: Clearance of influenza virus from the lung depends on migratory langerin $+C D 11 b$ - but not plasmacytoid dendritic cells. J Exp Med 2008, 205:1621-1634.

56. Nobs SP, Schneider C, Heer AK, Huotari J, Helenius A, Kopf M: PI3Kgamma Is Critical for Dendritic Cell-Mediated CD8+ T Cell Priming and Viral Clearance during Influenza Virus Infection. PLoS Pathog 2016, 12:e1005508.

57. Soto JA, Galvez NMS, Andrade CA, Pacheco GA, Bohmwald K, Berrios RV, Bueno SM, Kalergis AM: The Role of Dendritic Cells During Infections Caused by Highly Prevalent Viruses. Front Immunol 2020, 11:1513.

58. Vasilevsky S, Colino J, Puliaev R, Canaday DH, Snapper CM: Macrophages pulsed with Streptococcus pneumoniae elicit a $T$ cell-dependent antibody response upon transfer into naive mice. J Immunol 2008, 181:1787-1797.

59. Mirzayan MJ, Probst C, Krettek C, Samii M, Pape HC, van Griensven M, Samii A: Systemic effects of isolated brain injury: an experimental animal study. Neurol Res 2008, 30:457-460.

60. Li M, Li F, Luo C, Shan Y, Zhang L, Qian Z, Zhu G, Lin J, Feng H: Immediate splenectomy decreases mortality and improves cognitive function of rats after severe traumatic brain injury. J Trauma 2011, 71:141-147.

61. Alam A, Thelin EP, Tajsic T, Khan DZ, Khellaf A, Patani R, Helmy A: Cellular infiltration in traumatic brain injury. $J$ Neuroinflammation 2020, 17:328.

62. Khatri N, Thakur M, Pareek V, Kumar S, Sharma S, Datusalia AK: Oxidative Stress: Major Threat in Traumatic Brain Injury. CNS Neurol Disord Drug Targets 2018, 17:689-695.

63. Angeloni C, Prata C, Dalla Sega FV, Piperno R, Hrelia S: Traumatic brain injury and NADPH oxidase: a deep relationship. Oxid Med Cell Longev 2015, 2015:370312.

64. Prass K, Meisel C, Hoflich C, Braun J, Halle E, Wolf T, Ruscher K, Victorov IV, Priller J, Dirnagl U, et al: Stroke-induced immunodeficiency promotes spontaneous bacterial infections and is mediated by sympathetic activation reversal by poststroke $\mathbf{T}$ helper cell type 1-like immunostimulation. $J$ Exp Med 2003, 198:725-736.

65. Stewart IB, McKenzie DC: The human spleen during physiological stress. Sports Med 2002, 32:361-369.

66. Tracey KJ: Physiology and immunology of the cholinergic antiinflammatory pathway. J Clin Invest 2007, 117:289-296.

67. Lee ST, Chu K, Jung KH, Kim SJ, Kim DH, Kang KM, Hong NH, Kim JH, Ban JJ, Park HK, et al: Anti-inflammatory mechanism of intravascular neural stem cell transplantation in haemorrhagic stroke. Brain 2008, 131:616-629.

68. Keel M, Trentz O: Pathophysiology of polytrauma. Injury 2005, 36:691-709.

69. Lu J, Goh SJ, Tng PY, Deng YY, Ling EA, Moochhala S: Systemic inflammatory response following acute traumatic brain injury. Front Biosci (Landmark Ed) 2009, 14:3795-3813.

70. Weaver LC, Bao F, Dekaban GA, Hryciw T, Shultz SR, Cain DP, Brown A: CD11d integrin blockade reduces the systemic inflammatory response syndrome after traumatic brain injury in rats. Exp Neurol 2015, 271:409-422.

71. Wilcockson DC, Campbell SJ, Anthony DC, Perry VH: The systemic and local acute phase response following acute brain injury. $J$ Cereb Blood Flow Metab 2002, 22:318-326. 
72. Rathinam C: The 'inflammatory' control of hematopoietic stem cells. Oncotarget 2015, 6:19938-19939.

73. Baldridge MT, King KY, Goodell MA: Inflammatory signals regulate hematopoietic stem cells. Trends Immunol 2011, 32:57-65.

\section{Ethics declarations}

Ethics approval: This study was approved by the University of Maryland School of Medicine Institutional Animal Care and Use Committee (IACUC). All experiments were performed in accordance with the National Institutes of Health Guidelines on the Use of Laboratory Animals.

\section{Consent for publication}

Not applicable

\section{Competing interests}

774 The authors declare no competing interests. 


\section{Figure 1. TBI leads to altered numbers and distribution of DC subsets at the early phase.}

A. FACS plots indicating frequencies of CD11 $\mathrm{c}^{+} \mathrm{MHC}-\mathrm{Class} \mathrm{II}^{\mathrm{high}} \mathrm{CDCs}$ in the spleen of Sham, d1-TBI and d3-TBI mice. Data are representative of two independent experiments.

B. Cumulative frequencies (left) and absolute numbers (right) of cDCs in the spleen of Sham $(n=4)$, d1-TBI $(n=5)$ and d3-TBI $(n=5)$ mice. Data are representative of two independent experiments.

C. FACS plots indicating frequencies of $\mathrm{CD}^{+} \mathrm{CD} 11 \mathrm{~b}-\mathrm{cDC} 1, \mathrm{CD} 8 \mathrm{CD} 11 \mathrm{~b}^{+} \mathrm{cDC} 2$ and CD8CD11b-immature cDCs within pre-gated CD11 $\mathrm{c}^{+}$MHC-Class I $^{\text {high }} \mathrm{cDCs}$ in the spleen of Sham $(n=4)$, d1-TBI $(n=5)$ and d3-TBI $(n=5)$ mice. Data are representative of two independent experiments.

D-F. Relative frequencies (left), overall frequencies (middle) and absolute numbers (right) of cDC1 (D), cDC2 (E) and immature cDCs (F) subsets in the spleen of Sham $(n=4), d 1-T B I$ $(n=5)$ and d3-TBI $(n=5)$ mice. Data are representative of two independent experiments.

G. FACS plots indicating frequencies of PDCA $1{ }^{+} \mathrm{CD} 11 \mathrm{c}^{\mathrm{int}} \mathrm{pDCs}$ and PDCA1 $1{ }^{-} \mathrm{CD} 11 \mathrm{c}^{\text {high }} \mathrm{cDCs}$ in the spleen of Sham $(n=4)$, d1-TBI $(n=5)$ and d3-TBI $(n=5)$ mice. Data are representative of two independent experiments.

H \& I. Overall frequencies (left) and absolute numbers (right) of pDCs (H) and cDCs (I) in the spleen of Sham $(n=4), d 1-T B I(n=5)$ and d3-TBI $(n=5)$ mice. Data are representative of two independent experiments.

J. FACS plots indicating frequencies of PDCA $1{ }^{+} \mathrm{CD} 11 \mathrm{c}^{\mathrm{int}} \mathrm{pDCs}$ and PDCA1-CD $11 \mathrm{c}^{\text {high }} \mathrm{cDCs}$ in the BM of Sham $(n=4), d 1-T B I(n=5)$ and d3-TBI $(n=5)$ mice. Data are representative of two independent experiments.

K. Overall frequencies (left) and absolute numbers (right) of pDCs in the BM of Sham (n=4), d1-TBI $(n=5)$ and d3-TBI $(n=5)$ mice. Data are representative of two independent experiments.

L. FACS plots indicating frequencies of CD11 $\mathrm{c}^{+} \mathrm{MHC}-\mathrm{Class} \mathrm{II}^{\mathrm{high}} \mathrm{cDCs}$ in the BM of Sham $(n=4), d 1-T B I(n=5)$ and d3-TBI $(n=5)$ mice. Data are representative of two independent experiments.

M. Overall frequencies (left) and absolute numbers (right) of cDCs in the BM of Sham $(n=4)$, d1-TBI $(n=5)$ and d3-TBI $(n=5)$ mice. Data are representative of two independent experiments. All data represent mean \pm SEM. Mann-Whitney non-parametric tests were used to assess statistical significance $(* \mathrm{P}<0.05, * * \mathrm{P}<0.01, * * * \mathrm{P}<0.001$, **** $\mathrm{P}<0.0001)$. 
Figure 2. TBI causes changes in DC pool and functions at the late phase.

828

829

830

831

832

833

834

835

836

837

838

839

840

841

842

843

844

845

846

847

848

849

850

851

852

853

854

855

856

857

858

859

860

861

862

863

864

865

866

867

868

869

870

871

872

873

874

A. Relative frequencies (left) and absolute numbers (right) of cDCs in the spleen of Sham $(n=4)$ and $d 7-T B I(n=5)$ mice. Data are representative of two independent experiments.

B. Relative frequencies (left) and absolute numbers (right) of $\mathrm{cDC} 1$ subset in the spleen of Sham $(n=4)$ and d7-TBI $(n=5)$ mice. Data are representative of two independent experiments.

C. Relative frequencies (left) and absolute numbers (right) of cDC2 subset in the spleen of Sham $(n=4)$ and d7-TBI $(n=5)$ mice. Data are representative of two independent experiments.

D. Relative frequencies (left) and absolute numbers (right) of immature cDC subset in the spleen of Sham $(n=4)$ and d7-TBI $(n=5)$ mice. Data are representative of two independent experiments.

E. Relative frequencies (left) and absolute numbers (right) of pDC subset in the spleen of Sham $(n=4)$ and d7-TBI $(n=5)$ mice. Data are representative of two independent experiments.

F. Relative frequencies (left) and absolute numbers (right) of PDCA1-CD11 $\mathrm{c}^{\text {high }} \mathrm{cDC}$ subset in the spleen of Sham $(n=4)$ and d7-TBI $(n=5)$ mice. Data are representative of two independent experiments.

G. Relative frequencies (left) and absolute numbers (right) of cDCs in the BM of Sham $(n=4)$ and d7-TBI $(n=5)$ mice. Data are representative of two independent experiments.

H. Relative frequencies (left) and absolute numbers (right) of cDC1 subset in the BM of Sham $(n=4)$ and d7-TBI $(n=5)$ mice. Data are representative of two independent experiments.

I. Relative frequencies (left) and absolute numbers (right) of cDC2 subset in the BM of Sham $(n=4)$ and d7-TBI $(n=5)$ mice. Data are representative of two independent experiments.

J. Relative frequencies (left) and absolute numbers (right) of pDC subset in the BM of Sham $(n=4)$ and d7-TBI $(n=5)$ mice. Data are representative of two independent experiments.

K. Relative frequencies (left) and absolute numbers (right) of PDCA1-CD11 $\mathrm{c}^{\text {high }} \mathrm{cDC}$ subset in the BM of Sham $(n=4)$ and d7-TBI $(n=5)$ mice. Data are representative of two independent experiments.

All data represent mean \pm SEM. Two-tailed student's $t$ tests were used to assess statistical significance $(* \mathrm{P}<0.05, * * \mathrm{P}<0.01, * * * \mathrm{P}<0.001, * * * * \mathrm{P}<0.0001)$.

Figure 3. TBI alters expression of expression levels of surface molecules involved in DC functions.

A-D. Surface expression levels of CD80 (A), CD86 (B), MHC-CI (C) and MHC-CII (D) in total cDC, cDC1, cDC2 and pDC subsets of spleen from Sham, d1- and d3-TBI mice. Shown were Geo-Mean Fluorescence Intensities (GMFI). 
E-G. Surface expression levels of CD80 (E), CD86 (F) and MHC-CII (G) in total cDC, cDC1, cDC2 and pDC subsets of spleen from Sham and d7-TBI mice. Shown were GMFI. and PDCA1 ${ }^{-C D} 11 c^{+} \mathrm{cDC}(\mathbf{I})$ subsets of the BM from Sham, d1- and d3-TBI mice. Shown were GMFI.

All data represent mean \pm SEM. Mann-Whitney non-parametric tests and two-tailed student's $\mathrm{t}$ tests were used to assess statistical significance $(* \mathrm{P}<0.05, * * \mathrm{P}<0.01, * * * \mathrm{P}<0.001, * * * * \mathrm{P}<$ $0.0001)$.

\section{Figure 4. TBI results in an imbalance among DC subsets of the circulatory and lymphatic systems.}

A. Relative frequencies of total $\mathrm{cDC}, \mathrm{cDC} 1$ and $\mathrm{cDC} 2$ subsets in the peripheral blood from Sham $(n=4)$ and $d 7$-TBI $(n=5)$ mice. Data are representative of three independent experiments.

B. Surface expression levels of MHC-CII in total $\mathrm{cDC}, \mathrm{cDC} 1$ and $\mathrm{cDC} 2$ subsets of peripheral blood from Sham $(n=4)$ and d7-TBI $(n=5)$ mice. Shown were GMFI. Data are representative of three independent experiments.

C. Relative frequencies of total $\mathrm{cDC}, \mathrm{cDC} 1, \mathrm{cDC} 2 \mathrm{pDC}$ subsets in the peripheral lymph nodes from Sham $(n=4)$ and d7-TBI $(n=5)$ mice. Data are representative of two independent experiments.

D. Surface expression levels of MHC-CII, CD80 and CD86 in total cDC, cDC1, cDC2 and pDC subsets of peripheral lymph nodes from Sham $(n=4)$ and d7-TBI $(n=5)$ mice. Shown were GMFI. Data are representative of two independent experiments.

E. Relative frequencies of total $\mathrm{cDC}, \mathrm{cDC} 1$ and $\mathrm{cDC} 2$ subsets in the mesenteric lymph nodes from Sham $(n=4)$ and $d 7-T B I(n=5)$ mice. Data are representative of two independent experiments.

F. Surface expression levels of MHC-CII, CD80 and CD86 in total cDC, cDC1, cDC2 and pDC subsets of mesenteric lymph nodes from Sham $(n=4)$ and d7-TBI $(n=5)$ mice. Shown were GMFI. Data are representative of two independent experiments.

All data represent mean \pm SEM. Two-tailed student's $t$ tests were used to assess statistical significance $(* \mathrm{P}<0.05, * * \mathrm{P}<0.01, * * * \mathrm{P}<0.001, * * * * \mathrm{P}<0.0001)$.

\section{Figure 5. TBI affects DC distribution in solid organs.}

A. Frequencies of CD11 $\mathrm{c}^{+} \mathrm{CII}{ }^{\text {high }} \mathrm{cDCs}$ within pre-gated $\mathrm{CD} 45^{+}$hematopoietic fraction of lungs from Sham $(n=4)$ and d7-TBI $(n=5)$ mice. Data are representative of two independent experiments. 
B. Frequencies of $\mathrm{CD} 103^{+} \mathrm{cDC} 1$ and $\mathrm{CD} 11 \mathrm{~b}^{+} \mathrm{cDC} 2$ subsets within $\mathrm{CD} 45^{+} \mathrm{CD} 11 \mathrm{c}^{+} \mathrm{CII}{ }^{\text {high }} \mathrm{cDCs}$ of lungs from Sham $(n=4)$ and $d 7-T B I(n=5)$ mice. Data are representative of two independent experiments.

C. Frequencies of $\mathrm{CD} 4^{+} \mathrm{cDC} 2$ and $\mathrm{CD} 44^{-} \mathrm{cDC} 2$ subsets within $\mathrm{CD}^{2} 5^{+} \mathrm{CD} 11 \mathrm{c}^{+} \mathrm{CII}^{\text {high }} \mathrm{CD} 103^{-}$ $\mathrm{CD} 11 \mathrm{~b}^{+} \mathrm{cDC} 2$ cells of lungs from Sham $(n=4)$ and $\mathrm{d} 7-\mathrm{TBI}(\mathrm{n}=5)$ mice. Data are representative of two independent experiments.

D. Frequencies of CD11 $\mathrm{c}^{\mathrm{in} P D C A} 1^{+} \mathrm{pDCs}$ within pre-gated $\mathrm{CD} 45^{+}$hematopoietic fraction of lungs from Sham $(n=4)$ and d7-TBI $(n=5)$ mice. Data are representative of two independent experiments.

E. Frequencies of $\mathrm{CD} 11 \mathrm{c}^{+} \mathrm{CII}$ high $c D C s$ within pre-gated $\mathrm{CD} 45^{+}$hematopoietic fraction of liver from Sham $(n=4)$ and d7-TBI $(n=5)$ mice. Data are representative of two independent experiments.

F. Frequencies of $\mathrm{CD} 103^{+} \mathrm{cDC} 1$ and $\mathrm{CD} 11 \mathrm{~b}^{+} \mathrm{cDC} 2$ subsets within $\mathrm{CD} 45^{+} \mathrm{CD} 11 \mathrm{c}^{+} \mathrm{CII}{ }^{\text {high }} \mathrm{cDCs}$ of liver from Sham $(n=4)$ and d7-TBI $(n=5)$ mice. Data are representative of two independent experiments.

G. Frequencies of $\mathrm{CD}_{4}^{+} \mathrm{cDC} 2$ and $\mathrm{CD} 4{ }^{-} \mathrm{cDC} 2$ subsets within $\mathrm{CD}^{4} 5^{+} \mathrm{CD} 11 \mathrm{c}^{+} \mathrm{CI}{ }^{\text {high }} \mathrm{CD} 103^{-}$ $\mathrm{CD} 11 \mathrm{~b}^{+} \mathrm{cDC} 2$ cells of liver from Sham $(\mathrm{n}=4)$ and $\mathrm{d} 7-\mathrm{TBI}(\mathrm{n}=5)$ mice. Data are representative of two independent experiments.

H. Frequencies of CD11 $\mathrm{c}^{\mathrm{in}} \mathrm{PDCA} 1^{+} \mathrm{pDCs}$ within pre-gated $\mathrm{CD} 45^{+}$hematopoietic fraction of liver from Sham $(n=4)$ and d7-TBI $(n=5)$ mice. Data are representative of two independent experiments.

I. Surface expression levels of MHC-CII in total $\mathrm{cDC}, \mathrm{cDC} 1, \mathrm{cDC} 2$ and $\mathrm{pDC}$ subsets of liver from Sham $(n=4)$ and d7-TBI $(n=5)$ mice. Shown were GMFI. Data are representative of two independent experiments.

J. Frequencies of $\mathrm{CD} 45^{+}$hematopoietic cells from skin of Sham $(n=4)$ and $d 7-T B I(n=5)$ mice. Data are representative of two independent experiments.

K. Frequencies of $\mathrm{CD} 11 \mathrm{c}^{+} \mathrm{CII}{ }^{\text {high }} \mathrm{cDCs}$ within pre-gated $\mathrm{CD} 45^{+}$hematopoietic fraction of skin from Sham $(n=4)$ and d7-TBI $(n=5)$ mice. Data are representative of two independent experiments.

961 L. Frequencies of $\mathrm{CD} 103^{+} \mathrm{CD} 207^{+}$dermal DCs within $\mathrm{CD} 45^{+} \mathrm{CD} 11 \mathrm{c}^{+} \mathrm{CII}$ high cells of skin from Sham $(n=4)$ and d7-TBI $(n=5)$ mice. Data are representative of two independent experiments.

M. Frequencies of CD103-CD207 ${ }^{+}$Langerhans Cells within CD45 ${ }^{+} \mathrm{CD} 11 \mathrm{c}^{+} \mathrm{CII}{ }^{\text {high }}$ cells of skin from Sham $(n=4)$ and d7-TBI $(n=5)$ mice. Data are representative of two independent experiments.

All data represent mean \pm SEM. Two-tailed student's $t$ tests were used to assess statistical significance $\left(* \mathrm{P}<0.05,{ }^{*} \mathrm{P}<0.01,{ }^{* * *} \mathrm{P}<0.001\right.$, $\left.* * * * \mathrm{P}<0.0001\right)$. 
Figure 6. TBI affects early differentiation of DC progenitors in the BM.

A. FACS plots indicating frequencies of $\mathrm{Lin}^{-c}-\mathrm{Kit}^{+} \mathrm{Flt3}^{+} \mathrm{CD} 115^{+} \mathrm{CDPs}$ and $\mathrm{Lin}^{-c}-\mathrm{Kit}^{+}$ Flt $3{ }^{+} \mathrm{CD} 115^{-}$pDC progenitors in the BM of Sham $(n=4), d 1-T B I(n=5)$ and $d 3-T B I(n=5)$ mice. Data are representative of two independent experiments.

B-D. Relative frequencies (B), overall frequencies $(\mathbf{C})$ and absolute numbers $(\mathbf{D})$ of Lin $^{-} \mathrm{c}-\mathrm{Kit}^{+}$ Flt $3{ }^{+} \mathrm{CD} 115^{+}$CDPs in the BM of Sham $(n=4), d 1-T B I(n=5)$ and d3-TBI $(n=5)$ mice. Data are representative of two independent experiments.

E-G. Relative frequencies (E), overall frequencies $(\mathbf{F})$ and absolute numbers $(\mathbf{G})$ of $\mathrm{Linc}^{-} \mathrm{-}-\mathrm{Kit}^{+}$ Flt $3{ }^{+}$CD115- $p$ DC progenitors in the BM of Sham $(n=4), d 1-T B I(n=5)$ and $d 3-T B I(n=5)$ mice. Data are representative of two independent experiments.

H-J. Relative frequencies $(\mathbf{H})$, overall frequencies $(\mathbf{I})$ and absolute numbers $(\mathbf{J})$ of CDPs in the BM of Sham $(n=4)$ and d7-TBI $(n=5)$ mice. Data are representative of two independent experiments.

K-M. Relative frequencies (K), overall frequencies (L) and absolute numbers $(\mathbf{M})$ of pDC progenitors in the BM of Sham $(n=4)$ and d7-TBI $(n=5)$ mice. Data are representative of two independent experiments.

All data represent mean \pm SEM. Mann-Whitney non-parametric tests and two-tailed student's $\mathrm{t}$ tests were used to assess statistical significance $(* \mathrm{P}<0.05, * * \mathrm{P}<0.01, * * * \mathrm{P}<0.001$, **** $\mathrm{P}<$ $0.0001)$.

\section{Figure 7. TBI results in diminished levels of ROS in DC subsets and Progenitors.}

A. Histograms indicating intracellular ROS levels in $\mathrm{CD}_{11} \mathrm{c}^{+} \mathrm{CII}^{+}$splenic $\mathrm{cDCs}$ from sham $(n=4), d 1-T B I(n=5)$ and d3-TBI $(n=5)$ mice. Shown were the frequencies of ROS ${ }^{\text {high }}$ cells under the indicated gates. Cells treated with DMSO served as negative controls.

B. Frequencies of gated $\mathrm{ROS}^{\text {high }} \mathrm{CD} 11 \mathrm{c}^{+} \mathrm{CII}^{+}$splenic cDCs (top) and total intracellular ROS levels (GMFI) in CD11 $\mathrm{c}^{+} \mathrm{CII}^{+}$splenic cDCs (bottom) from sham $(\mathrm{n}=4)$, d1-TBI $(n=5)$ and d3TBI $(n=5)$ mice.

C. Histograms indicating intracellular ROS levels in $\mathrm{CD}^{+} \mathrm{CD} 11 \mathrm{~b}-\mathrm{CD} 11 \mathrm{c}^{+} \mathrm{CII}^{+}$splenic $\mathrm{cDC} 1$ subset from sham $(n=4), d 1-T B I(n=5)$ and d3-TBI $(n=5)$ mice. Shown were the frequencies of ROS $^{\text {high }}$ cells under the indicated gates. Cells treated with DMSO served as negative controls.

D. Frequencies of gated $\mathrm{ROS}^{\text {high }} \mathrm{CD} 8^{+} \mathrm{CD} 11 \mathrm{~b}-\mathrm{CD} 11 \mathrm{c}^{+} \mathrm{CII}{ }^{+}$splenic $\mathrm{cDC} 1$ subset (top) and total intracellular ROS levels (GMFI) in $\mathrm{CD}^{+} \mathrm{CD} 11 \mathrm{~b}^{-} \mathrm{CD} 11 \mathrm{c}^{+} \mathrm{CII}^{+}$splenic $\mathrm{cDC} 1$ subset (bottom) from sham $(n=4), d 1-T B I(n=5)$ and $d 3-T B I(n=5)$ mice.

E. Histograms indicating intracellular ROS levels in CD8-CD11 ${ }^{+} \mathrm{CD} 11 \mathrm{c}^{+} \mathrm{CII}^{+}$splenic cDC2 subset from sham $(n=4)$, d1-TBI $(n=5)$ and d3-TBI $(n=5)$ mice. Shown were the frequencies of ROS $^{\text {high }}$ cells under the indicated gates. Cells treated with DMSO served as negative controls. 
1022 F. Frequencies of gated $\mathrm{ROS}^{\text {high }} \mathrm{CD} 8 \mathrm{CD} 11 \mathrm{~b}^{+} \mathrm{CD} 11 \mathrm{c}^{+} \mathrm{CII}{ }^{+}$splenic $\mathrm{cDC} 2$ (top) and total intracellular ROS levels (GMFI) in $\mathrm{CD} 8 \mathrm{CD} 11 \mathrm{~b}^{+} \mathrm{CD} 11 \mathrm{c}^{+} \mathrm{CII}^{+}$splenic $\mathrm{cDC} 2$ (bottom) from sham $(n=4)$, d1-TBI $(n=5)$ and d3-TBI $(n=5)$ mice.

G. Histograms indicating intracellular ROS levels in $\mathrm{CD} 8 \mathrm{CD} 11 \mathrm{~b}-\mathrm{CD} 11 \mathrm{c}^{+} \mathrm{CII}^{+}$splenic immature cDCs from sham $(n=4)$, d1-TBI $(n=5)$ and d3-TBI $(n=5)$ mice. Shown were the frequencies of ROS ${ }^{\text {high }}$ cells under the indicated gates. Cells treated with DMSO served as negative controls.

H. Frequencies of gated $\mathrm{ROS}^{\text {high }} \mathrm{CD} 8 \mathrm{CD} 11 \mathrm{~b}-\mathrm{CD} 11 \mathrm{c}^{+} \mathrm{CII}{ }^{+}$splenic immature $\mathrm{cDCs}$ (top) and total intracellular ROS levels (GMFI) in CD8 CD11b CD11 $\mathrm{c}^{+} \mathrm{CII}^{+}$splenic immature $\mathrm{cDCs}$ (bottom) from sham $(n=4)$, d1-TBI $(n=5)$ and $d 3-T B I(n=5)$ mice.

I. Histograms indicating intracellular ROS levels in PDCA $1^{+} \mathrm{CD} 11 \mathrm{c}^{+}$splenic $\mathrm{pDCs}$ from sham $(n=4), d 1-T B I(n=5)$ and d3-TBI $(n=5)$ mice. Shown were the frequencies of ROS ${ }^{\text {high }}$ cells under the indicated gates. Cells treated with DMSO served as negative controls.

J. Frequencies of gated ROS high PDCA $1{ }^{+} \mathrm{CD} 11 \mathrm{c}^{+}$splenic $\mathrm{pDCs}$ (top) and total intracellular ROS levels (GMFI) in PDCA1 ${ }^{+} \mathrm{CD} 11 \mathrm{c}^{+}$splenic pDCs (bottom) from sham $(\mathrm{n}=4)$, d1-TBI $(\mathrm{n}=5)$ and $\mathrm{d} 3-\mathrm{TBI}(\mathrm{n}=5)$ mice.

K-O. Histograms indicating intracellular ROS levels (GMFI) in total cDCs (K), cDC1 (L), cDC2 $(\mathbf{M})$, immature cDCs $(\mathbf{N})$ and $\mathrm{pDCs}(\mathbf{O})$ of the spleen from sham $(n=5)$ and $\mathrm{d} 7$-TBI $(\mathrm{n}=5)$ mice.

P. Frequencies of gated ROS ${ }^{\text {high }} \mathrm{Linc}^{-1}-\mathrm{Kit}^{+} \mathrm{Flt} 3^{+} \mathrm{CD} 115^{+} \mathrm{CDPs}$ (left) and total intracellular ROS levels (GMFI) in Linc-Kit ${ }^{+} \mathrm{Flt}{ }^{+} \mathrm{CD} 115^{+} \mathrm{CDPs}$ (right) of the BM of Sham (n=4), d1-TBI (n=5) and $\mathrm{d} 3$-TBI $(n=5)$ mice. Data are representative of two independent experiments.

All data represent mean \pm SEM. Mann-Whitney non-parametric tests and two-tailed student's $\mathrm{t}$ tests were used to assess statistical significance $\left({ }^{*} \mathrm{P}<0.05\right.$, ${ }^{*} * \mathrm{P}<0.01,{ }^{* * *} \mathrm{P}<$ $0.001, * * * * \mathrm{P}<0.0001)$ 
A

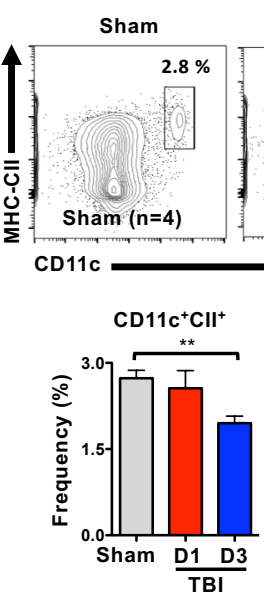

TBI (D1)
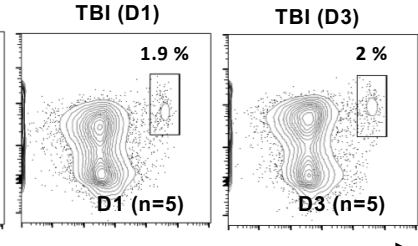

C

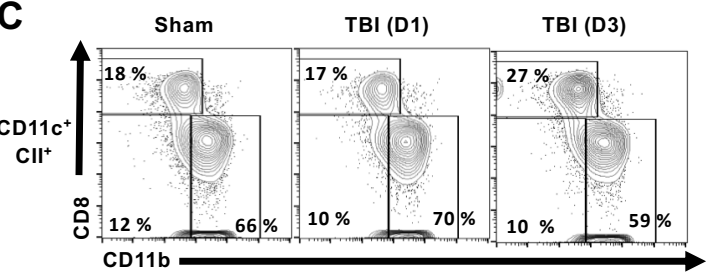

D

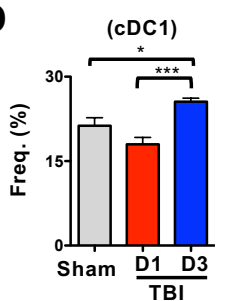

E

(cDC2)

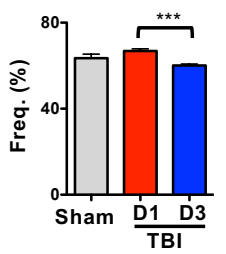

F

(CD8-CD11b-)

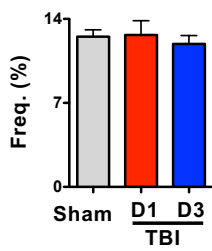

(cDC1)

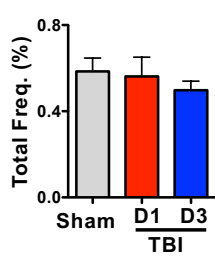

(cDC2)

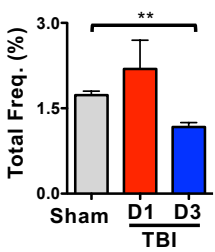

(CD8-CD11b-)

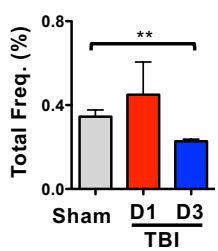

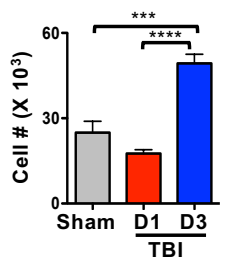

(CD8-CD11b-)

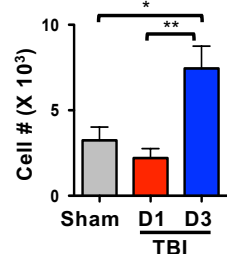

G

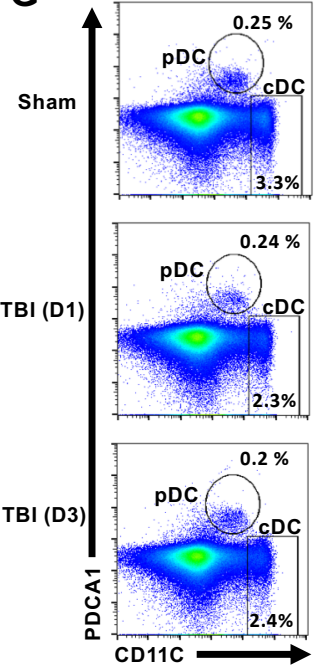

J

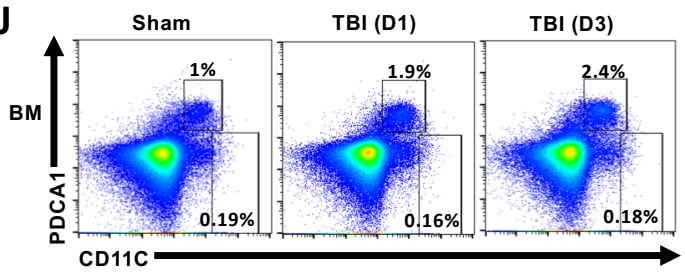

K

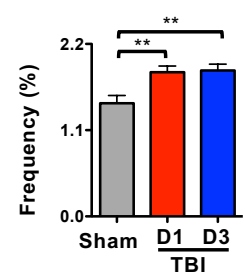

L

H
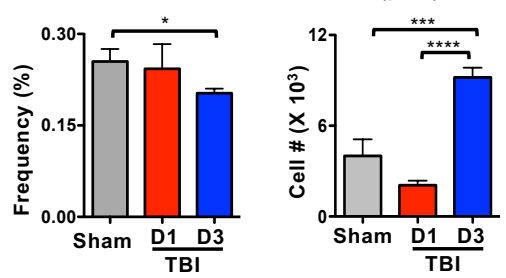

I
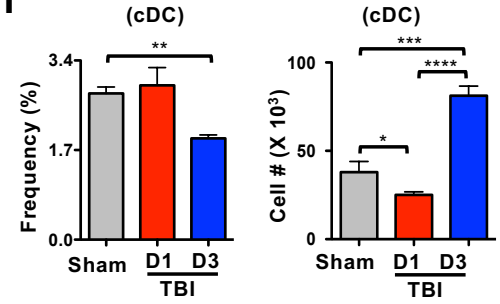

TBI (D3)

(pDC)
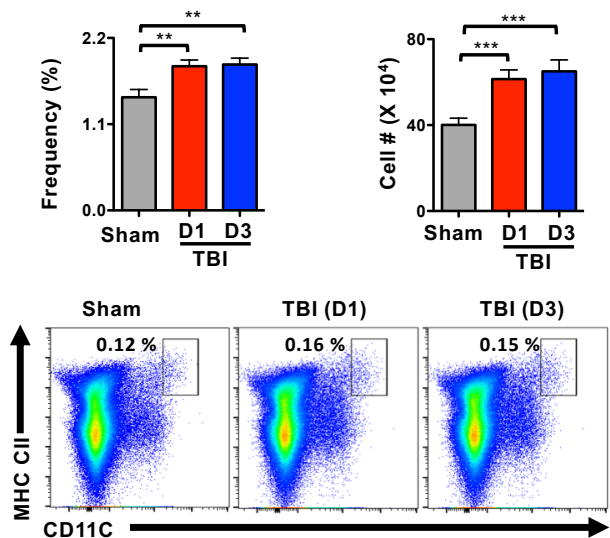

M

(cDC)

(cDC)
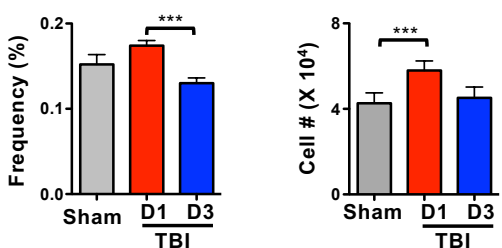

Figure 1. 
A
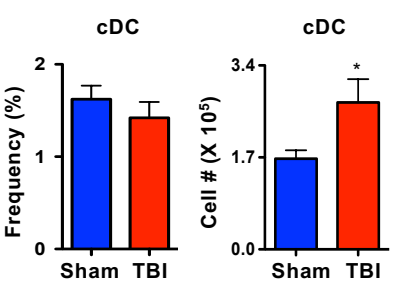

B
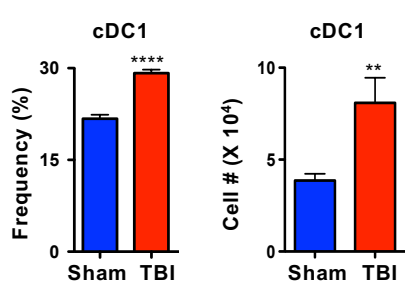

C

cDC2

cDC2

D CD8.CD11b-
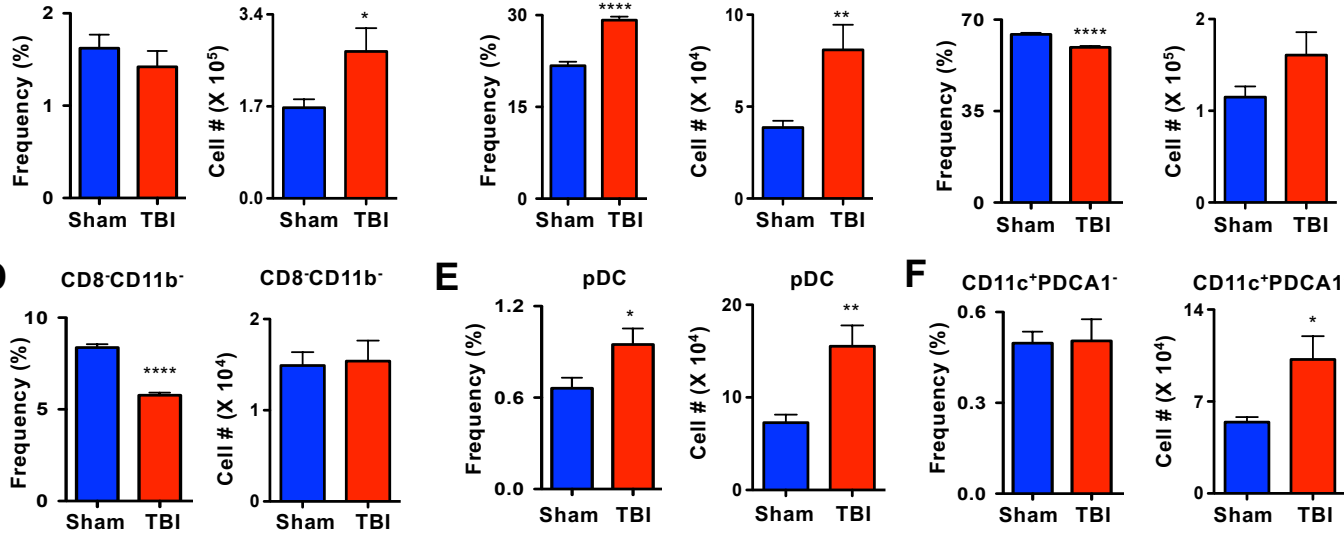

F CD11c ${ }^{+}$PDCA1 CD11C+PDCA1 -
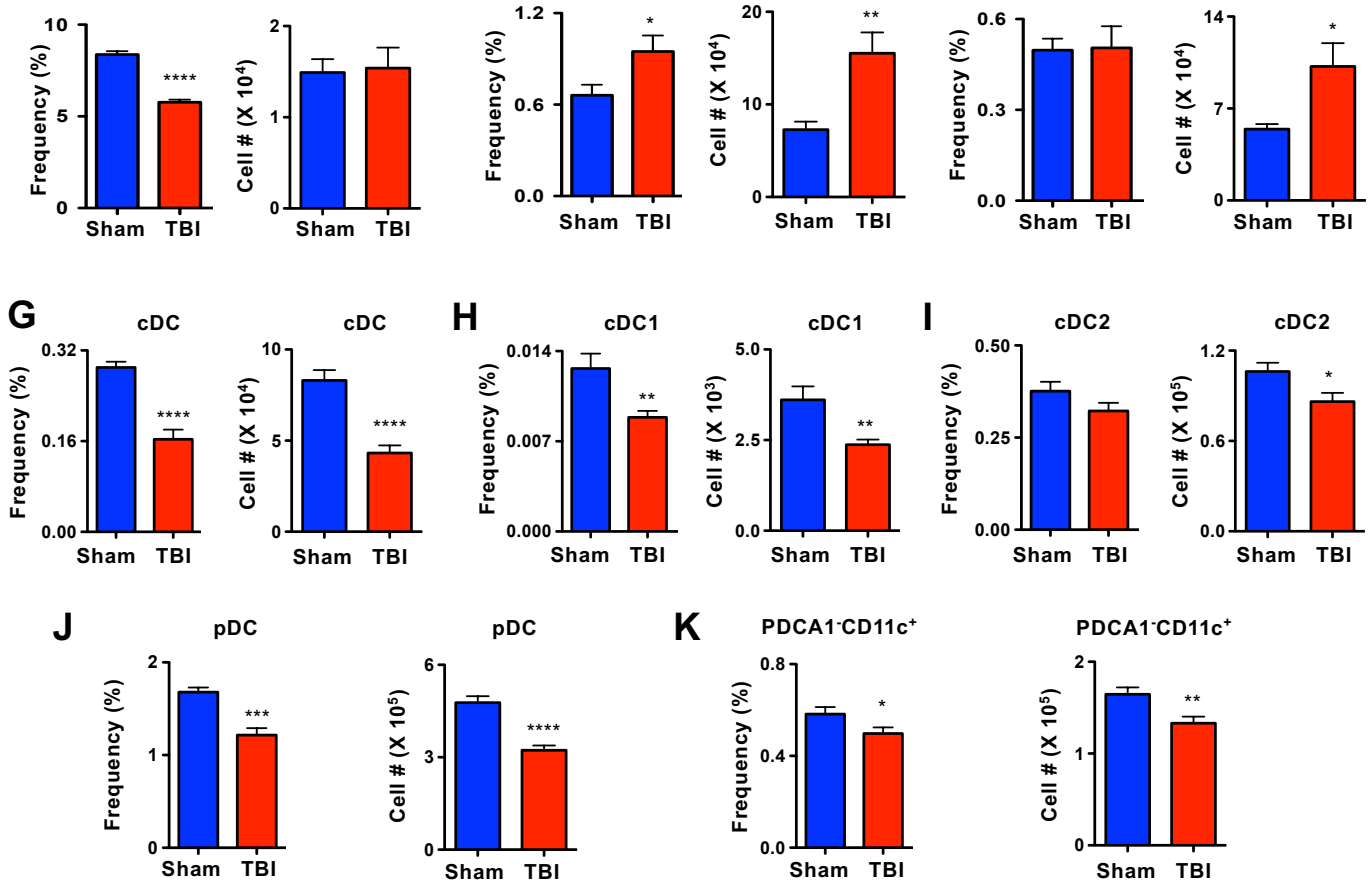

Figure 2. 
A
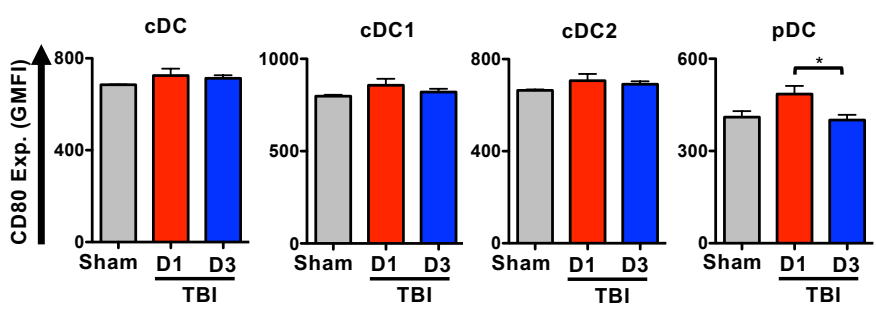

B
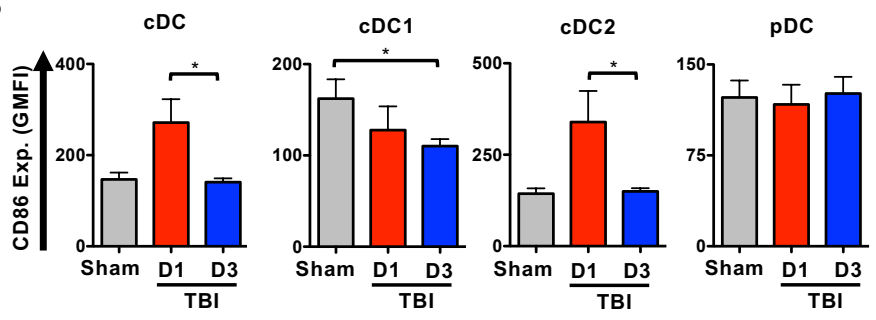

C
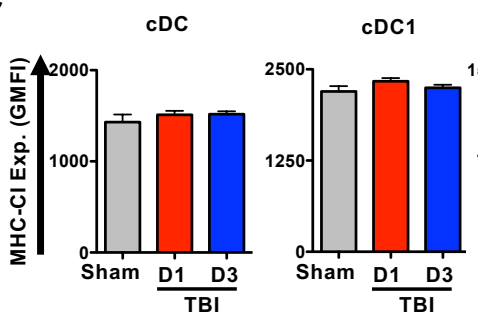

cDC2

pDC

D
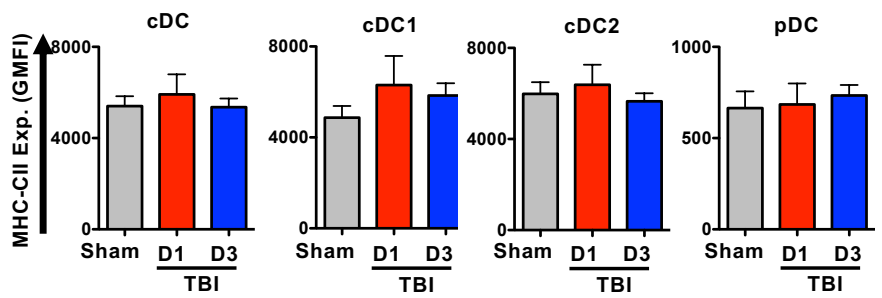

E
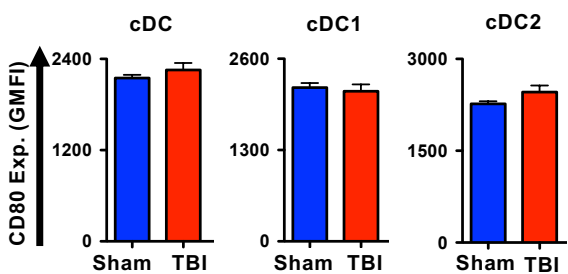

pDC

F
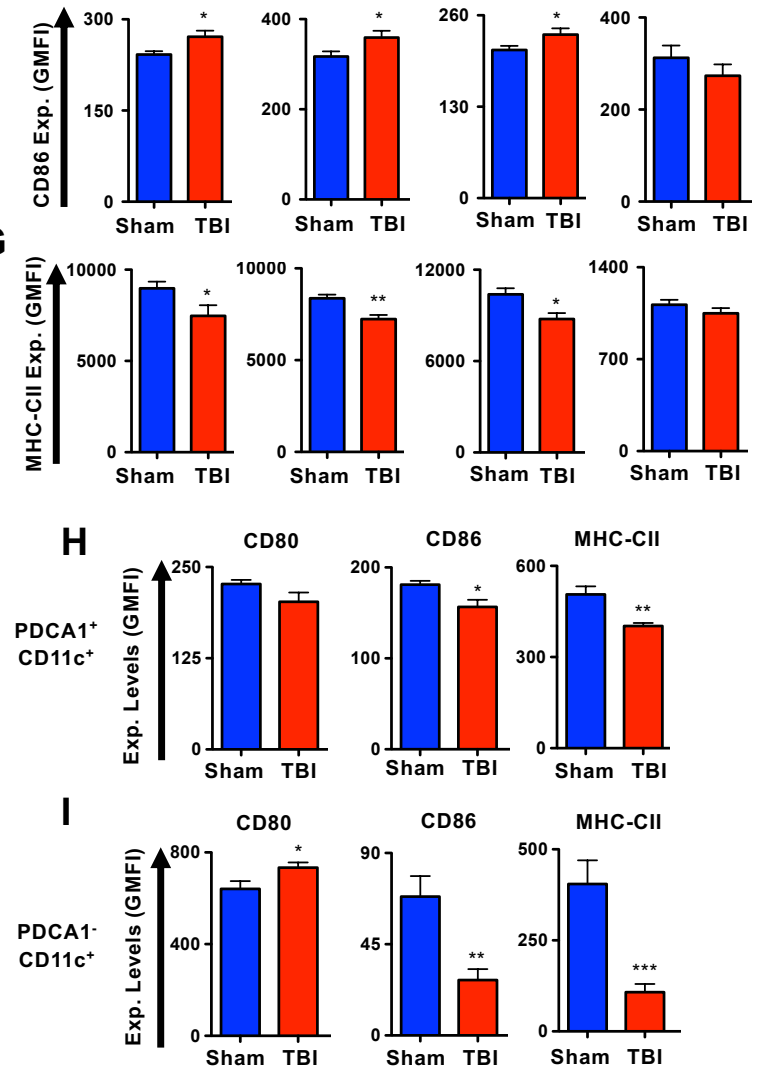

Figure 3. 
A
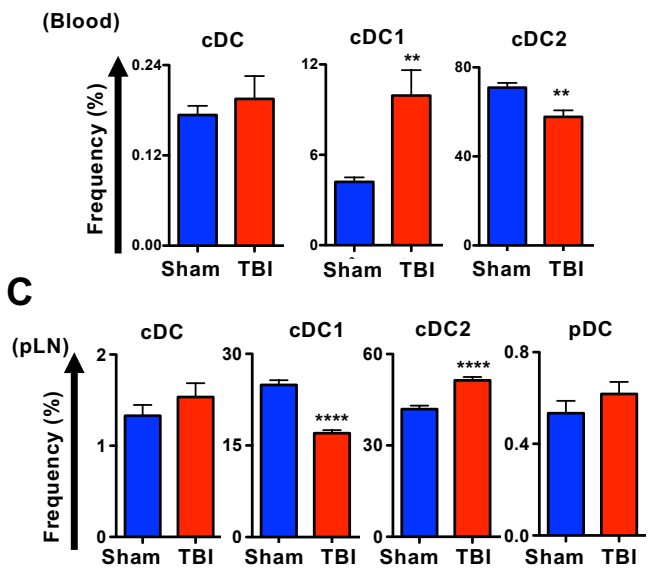

D

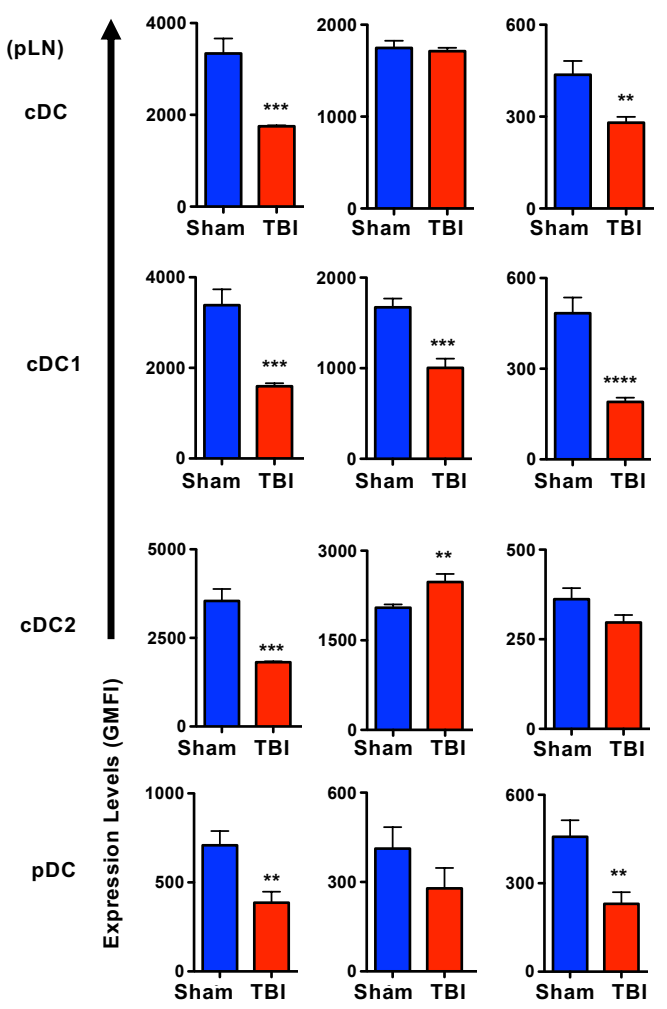

B

(MHC-CII)

(Blood)

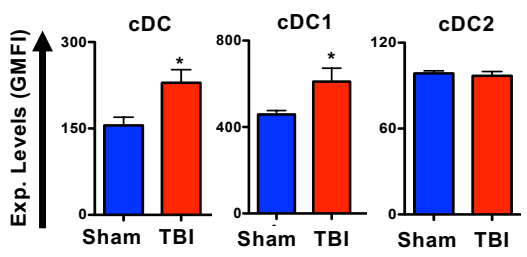

E
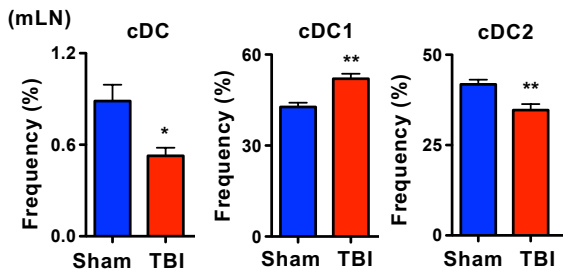

F

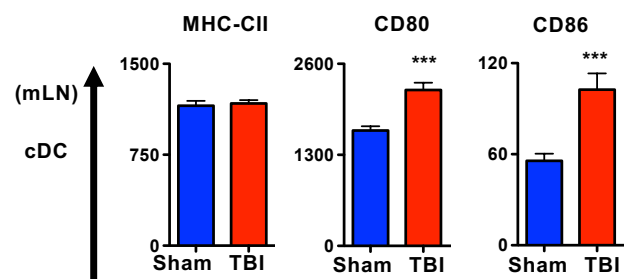

cDC1
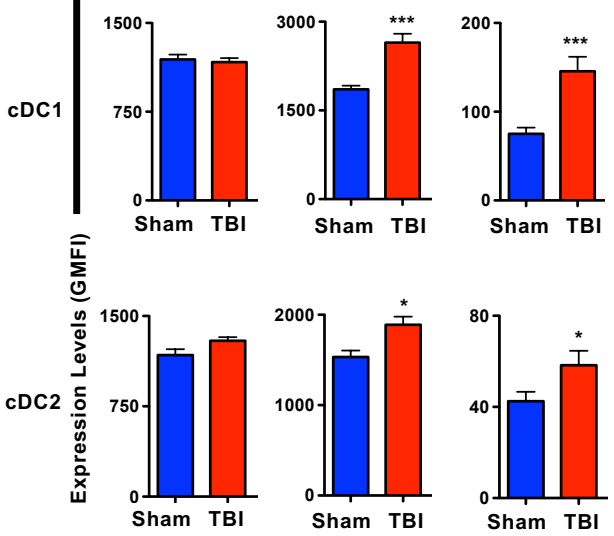

Figure 4. 
A

$\mathrm{CD} 11 \mathrm{c}^{+} \mathrm{CII}+\mathrm{CDC}$

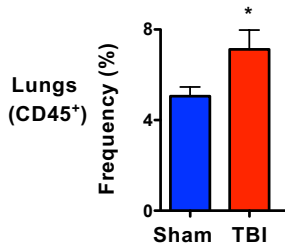

E
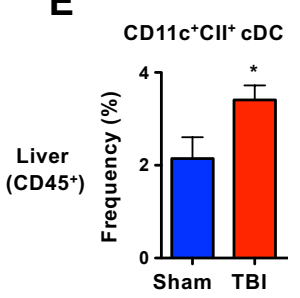

$\mathbf{F}$

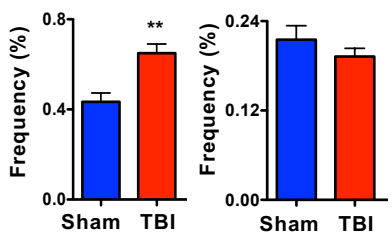

$\mathrm{CD}_{103^{+} \mathrm{CDC} 1 \quad \mathrm{CD} 11 \mathrm{~b}{ }^{+} \mathrm{CDC} 2}$
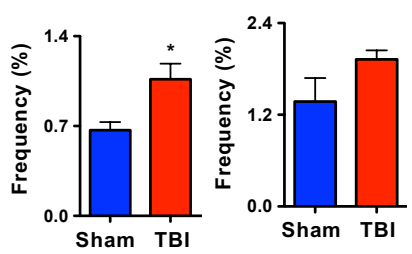

C

$\mathrm{CD}^{+}{ }^{+} \mathrm{CDC} 2$

CD4- cDC2

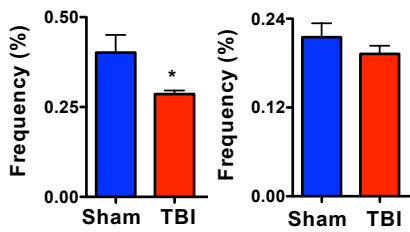

G

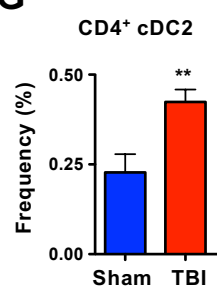

CD4 ${ }^{-}$CDC2
D

pDC

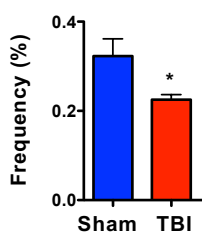

H

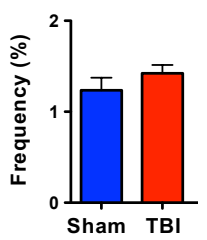

pDC

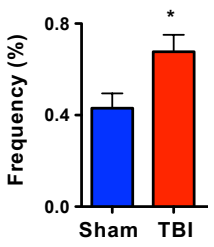

(MHC Class II)

I

cDC

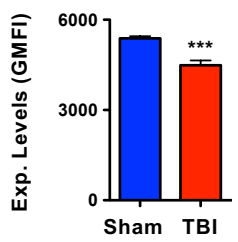

J

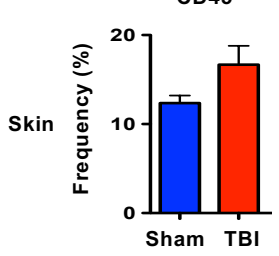

cDC1

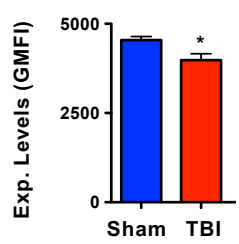

K

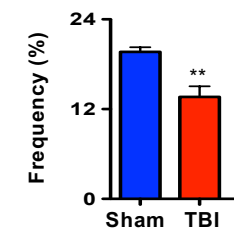

cDC2

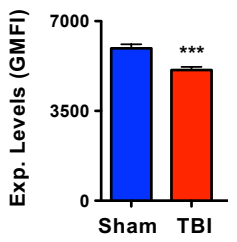

L (CD45 ${ }^{+}$CD11C+Cll+) $\mathrm{CD} 103^{+} \mathrm{CD} 207^{+}$

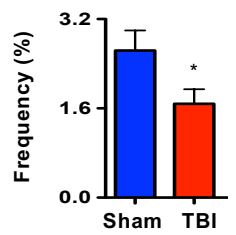

pDC

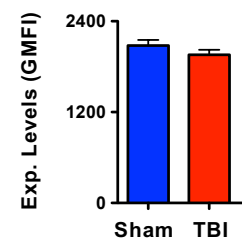

M (CD45 $\left.{ }^{+} \mathrm{CD} 11 \mathrm{C}+\mathrm{CII+}\right)$ CD103-CD207 ${ }^{+}$

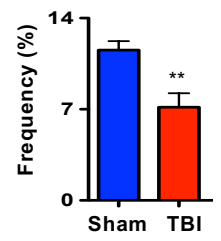

Figure 5. 
A
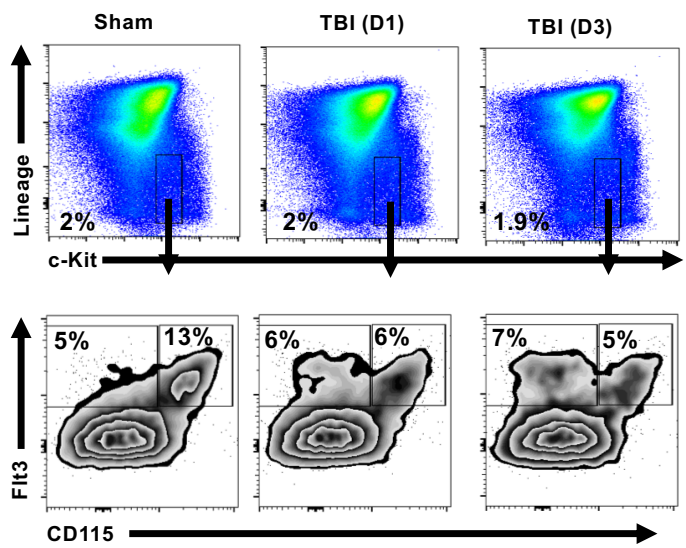

(Lin-C-Kit ${ }^{\text {int }} \mathrm{FIt} 3^{+} \mathrm{CD} 115^{+}$; Common DC Progenitors)

H
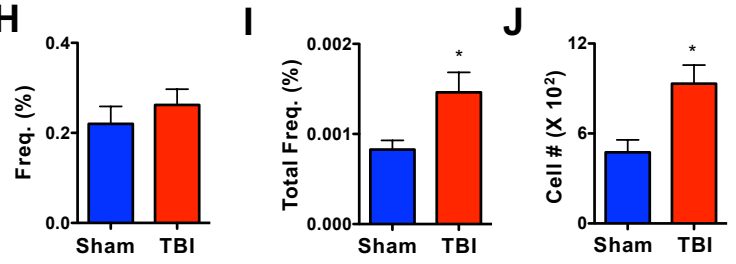

B

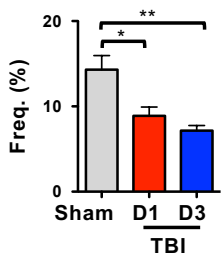

C

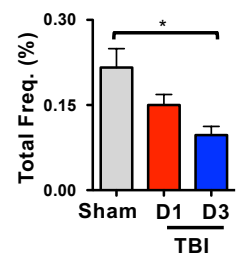

D

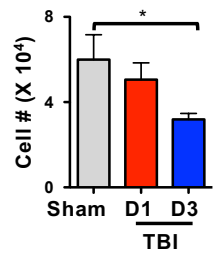

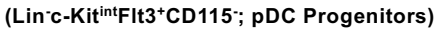
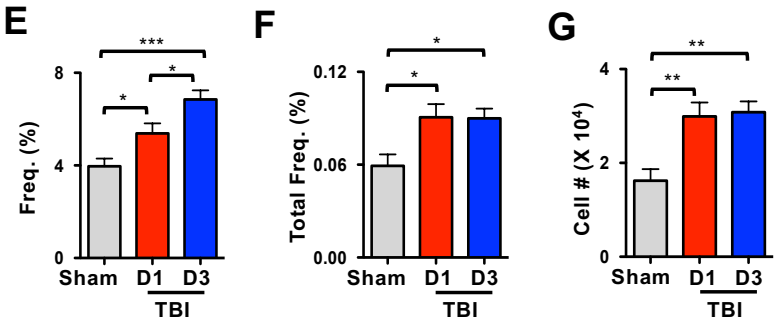

(Lin-c-Kit ${ }^{\text {intFIt3+CD115; pDC Progenitors) }}$

K

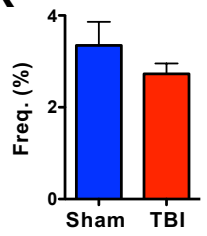

$\mathbf{L}$

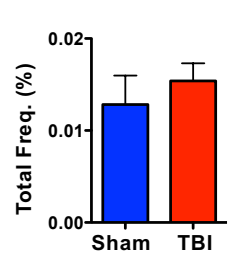

M

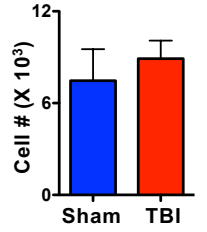

Figure 6. 

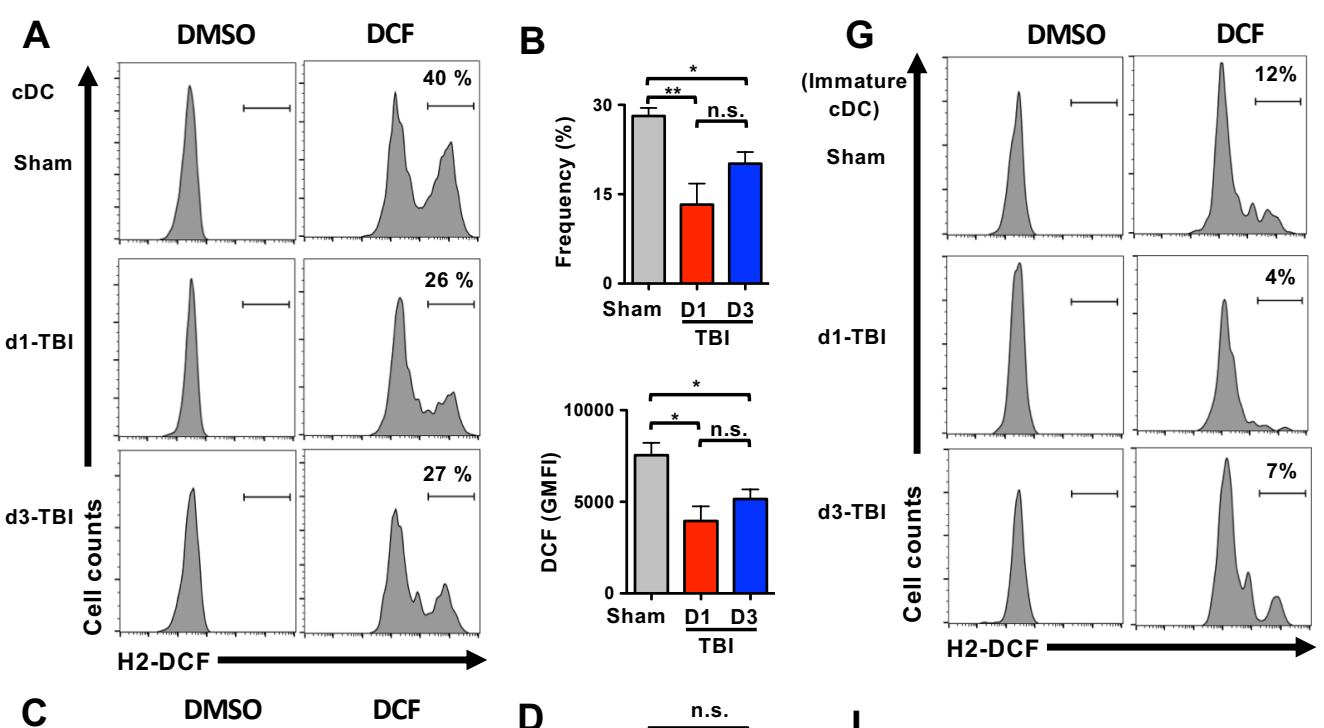

H
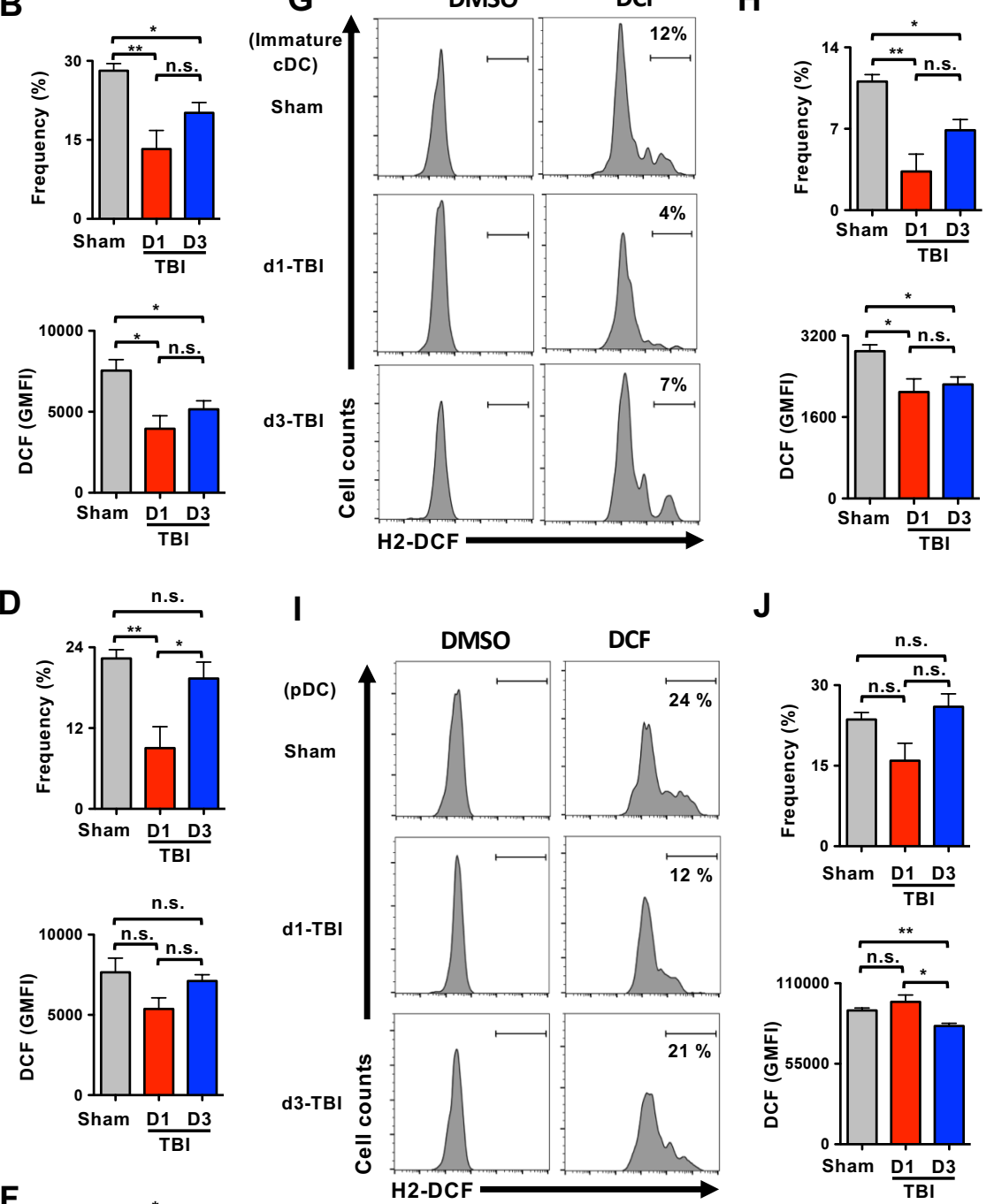

K
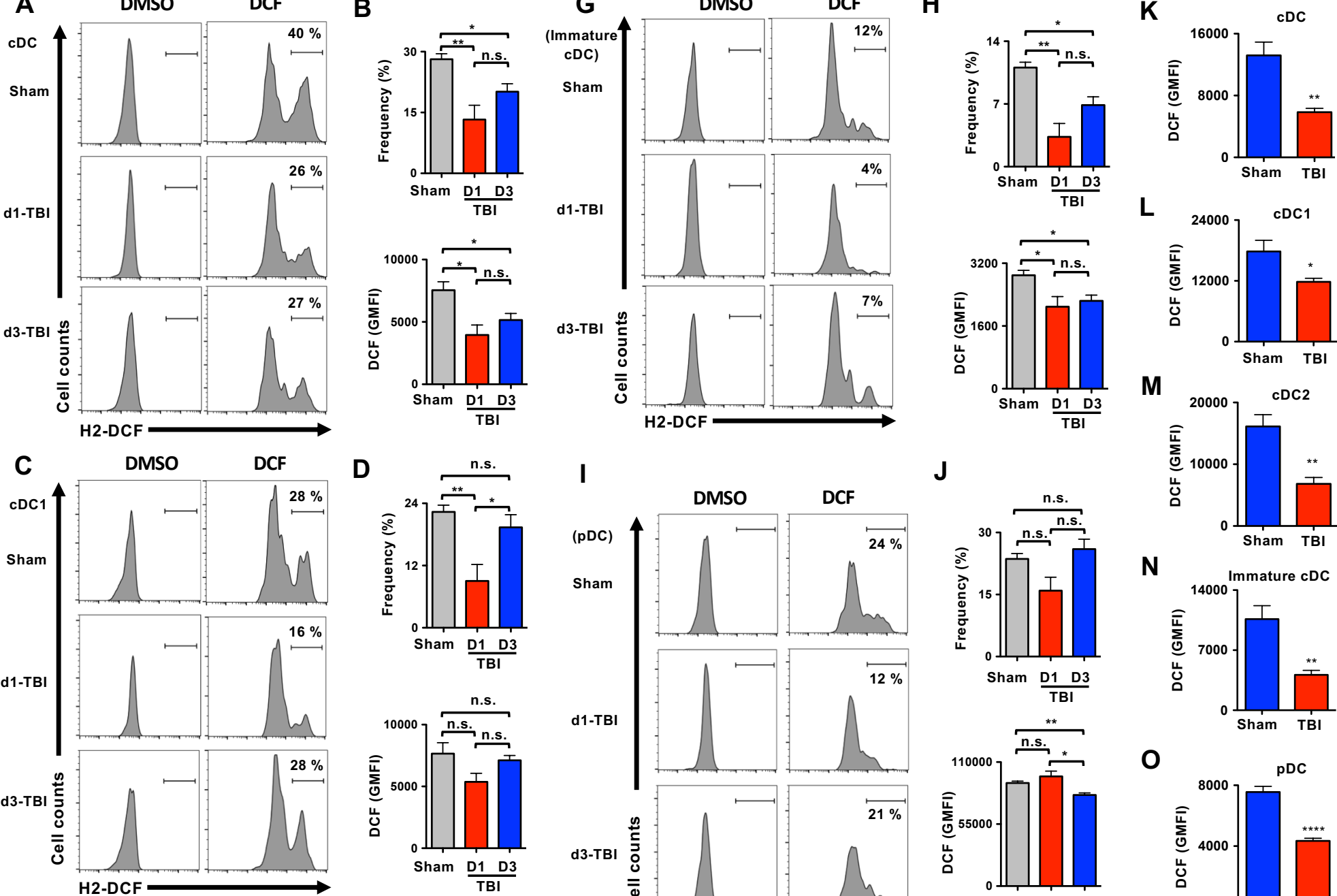

J
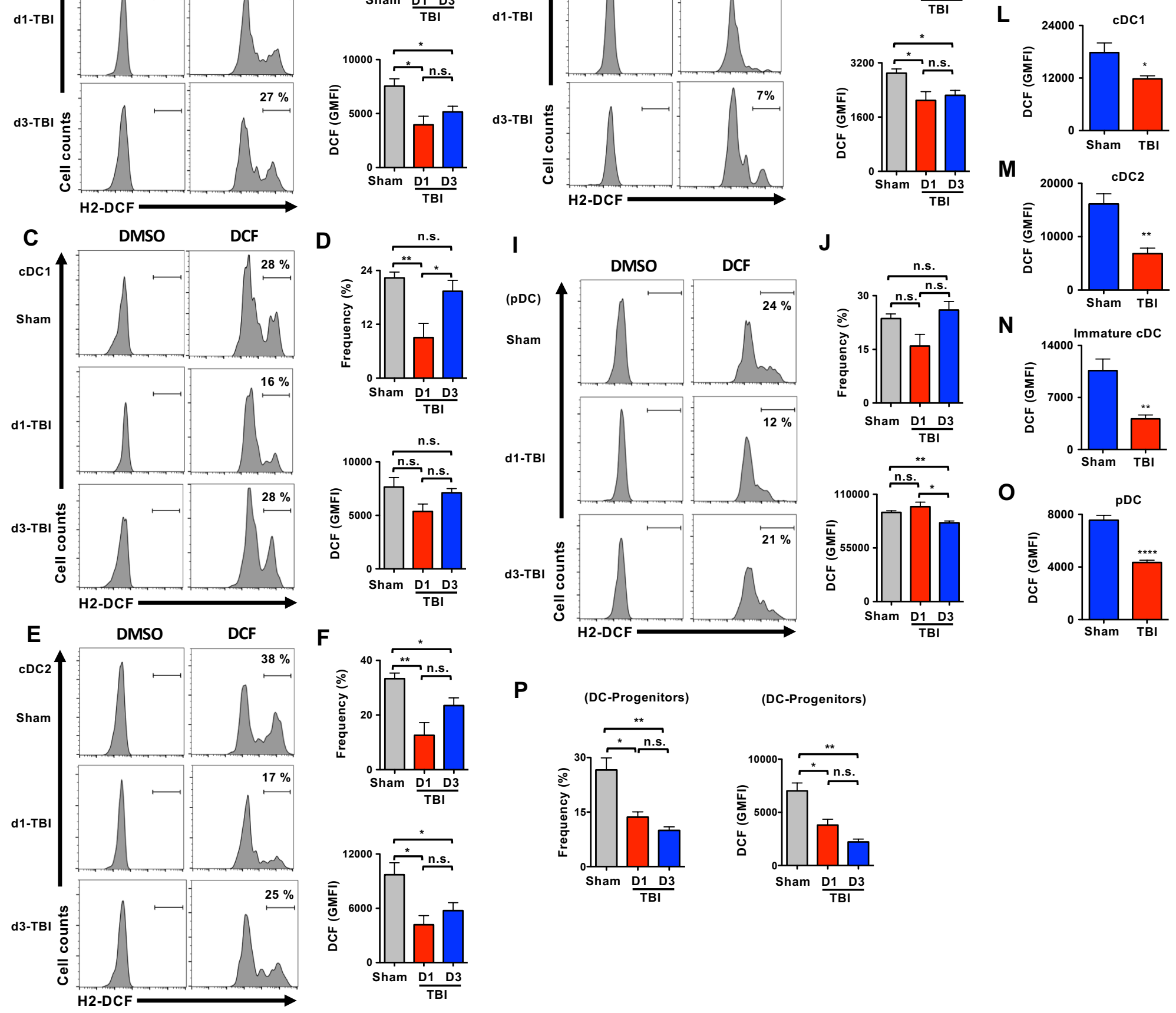

Figure 7.
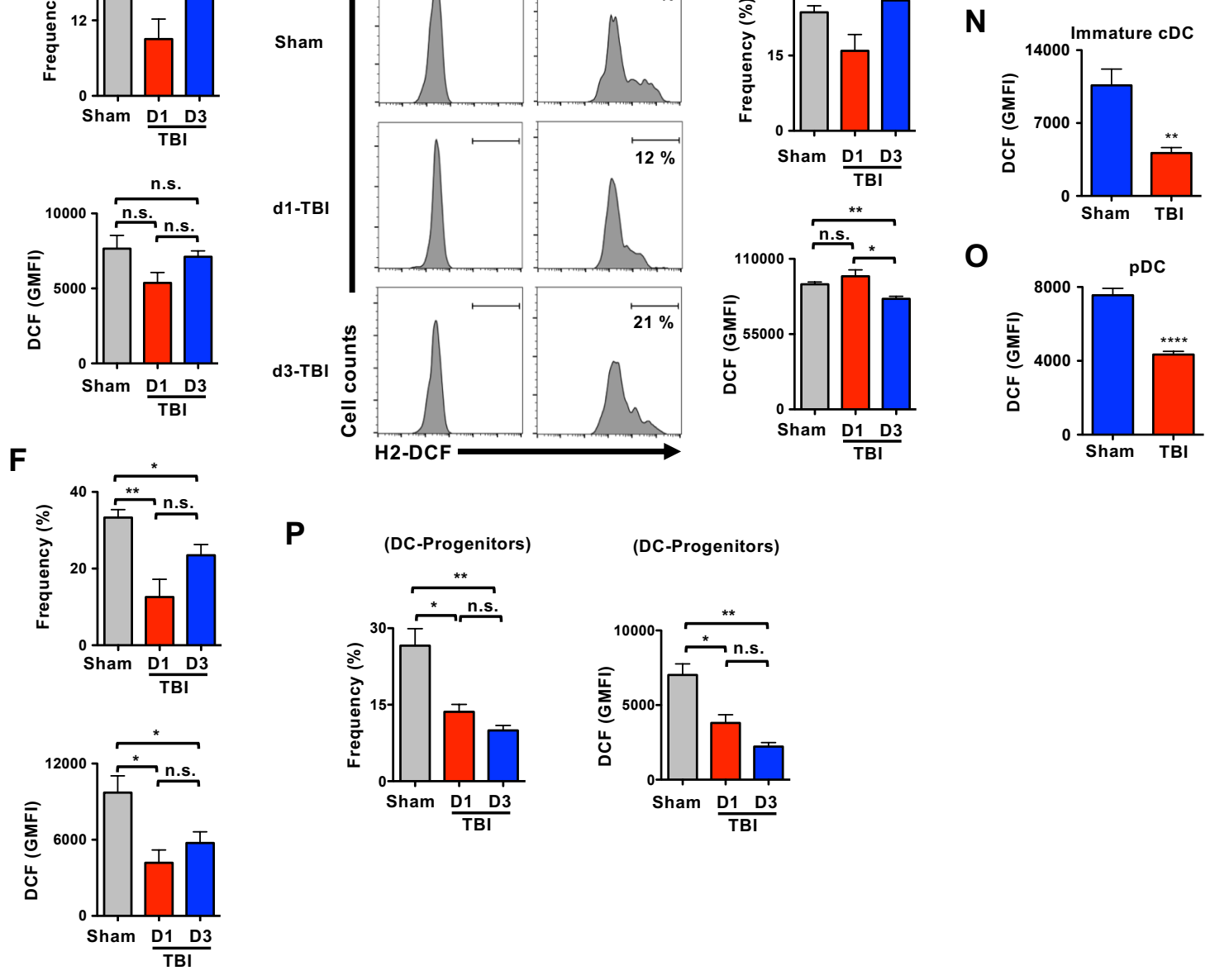